\title{
Principal Learning-Centered Leadership and Faculty Trust in the Principal
}

Shane Justin Farnsworth

Brigham Young University - Provo

Follow this and additional works at: https://scholarsarchive.byu.edu/etd

Part of the Educational Leadership Commons

\section{BYU ScholarsArchive Citation}

Farnsworth, Shane Justin, "Principal Learning-Centered Leadership and Faculty Trust in the Principal" (2015). Theses and Dissertations. 5514.

https://scholarsarchive.byu.edu/etd/5514

This Dissertation is brought to you for free and open access by BYU ScholarsArchive. It has been accepted for inclusion in Theses and Dissertations by an authorized administrator of BYU ScholarsArchive. For more information, please contact scholarsarchive@byu.edu, ellen_amatangelo@byu.edu. 
Principal Learning-Centered Leadership and Faculty Trust in the Principal

Shane Justin Farnsworth

A dissertation submitted to the faculty of

Brigham Young University

in partial fulfillment of the requirements for the degree of

Doctor of Education

Pamela R. Hallam, Chair

Sterling C. Hilton

LeGrand A. Richards

Clifford T. Mayes

Randall Davies

Department of Educational Leadership and Foundations

Brigham Young University

July 2015

Copyright $@ 2015$ Shane Justin Farnsworth

All Rights Reserved 


\title{
ABSTRACT \\ Principal Learning-Centered Leadership and Faculty Trust in the Principal
}

\author{
Shane Justin Farnsworth \\ Department of Educational Leadership and Foundations, BYU \\ Doctor of Education
}

Principals are increasingly held accountable for student achievement outcomes. Existing research has found principal leadership indirectly affects student achievement (Leithwood, Louis, Anderson, \& Wahlstrom, 2004. Principals face a problem when they are accountable for achievement outcomes and are dependent upon others and other variables to achieve those outcomes. Consequently, principals will benefit from a richer understanding of how their leadership indirectly affects student achievement.

Using the Vanderbilt Assessment of Leadership in Education (VAL-ED measurement of principal learning-centered leadership (Goldring, Porter, Murphy, Elliot, \& Cravens, 2009 and the Omnibus T-Scale measurement of faculty trust in the principal (Hoy \& Tschannen-Moran, 2003, researchers sought to better understand the relationship between the perceived learningcentered leadership of principals and faculty trust in those principals. Teachers from 59 schools in a suburban district in the Rocky Mountain region of the United States were surveyed to measure their perception of the learning-centered leadership of their principal and the faculty's trust in their principal.

The data from these surveys were analyzed using bivariate and multiple linear regression analyses to determine relationships between these two variables and other significant control variables. Principal learning-centered leadership was significantly and positively related to faculty trust in the principal; principals in this study with higher learning-centered leadership scores had higher faculty trust in principal scores. The $\mathrm{R}^{2}$ was .609 , indicating that approximately $60 \%$ of the variance in faculty trust in the principal was attributable to the principal's learning-centered leadership, school grade, and principal gender. Additionally, for the principals in this study every unit increase in perceived learning-centered leadership scores resulted in a 1.11 increase in faculty trust in the principal scores. The significance of the relationship was even stronger in schools with a $C$ academic achievement grade. In $C$ graded schools, every unit increase in principal learning-centered leadership scores resulted in a 2.31 increase in faculty trust in the principal scores.

Principals with higher levels of learning-centered leadership were rewarded with higher levels of faculty trust. The influence of learning-centered leadership on faculty trust in the principal was even stronger in schools labels lower in academic achievement. Principals seeking to influence the trust their faculty places should engage in those leadership practices associated with learning-centered leadership.

Keywords: instructional leadership, learning-centered leadership, trust 


\section{ACKNOWLEDGEMENTS}

This dissertation has been a significant undertaking in my life. Such an endeavor would not have been possible without the encouragement, support, guidance, and relationships I have with other wonderful people. They have all provided me with the greatest gift you can give another, opportunity. I wish to express my deepest appreciation to them.

- My wife Meri Ann is my best friend and my biggest advocate. She has consistently taken on more than her share of responsibilities, so that I may pursue additional opportunities. Anything of value I have accomplished I owe to our eternal relationship. Her sacrifice for me can only be repaid in my constant love and commitment to her.

- Our children, Parker, Miles, Cole, Paige, Noah, and Tate have also been significant supporters of dad and his degree. They keep me true to what matters most.

- My chair, Pam Hallam, has been a constant source of support, guidance and encouragement. I could not have had a better chair. She is a dear friend and colleague. My committee members have also provided guidance and support along the way. I especially appreciate Sterling Hilton's support in the analysis stage of this process.

- Finally, I appreciate the junior high principals, district office administration, and my other colleagues in Alpine School District who offer support and a meaningful environment and opportunity in which I can continue to practice the learning-centered leadership I have studied in theory. 


\section{TABLE OF CONTENTS}

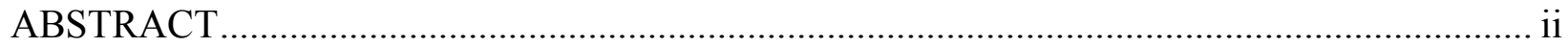

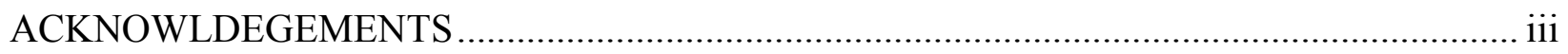

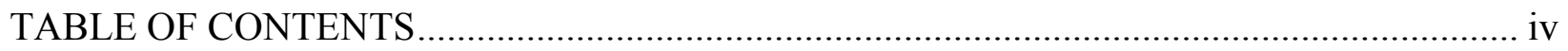

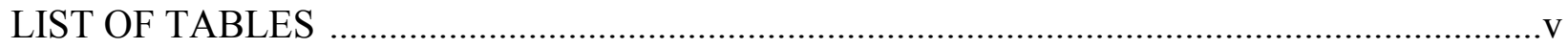

DESCRIPTION OF DISSERTATION CONTENT AND STRUCTURE ............................... vi

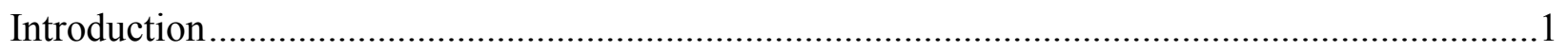

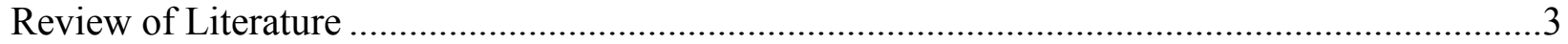

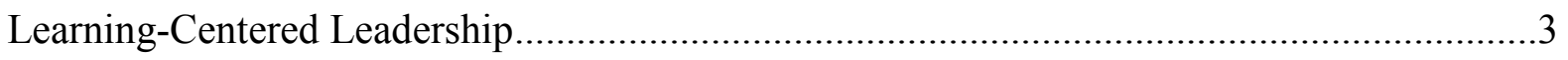

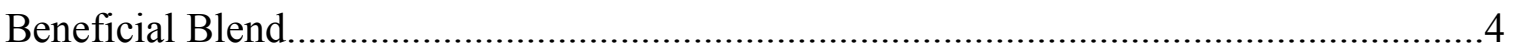

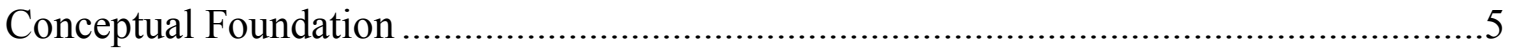

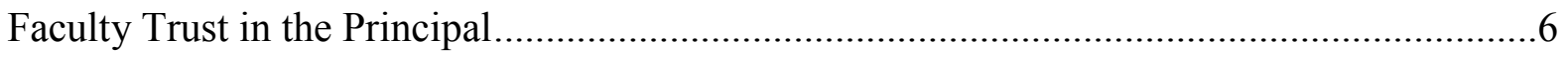

Classification, Definition, and Dimensions ...........................................................

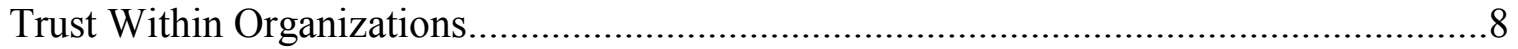

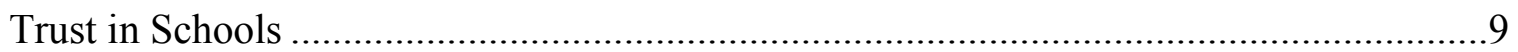

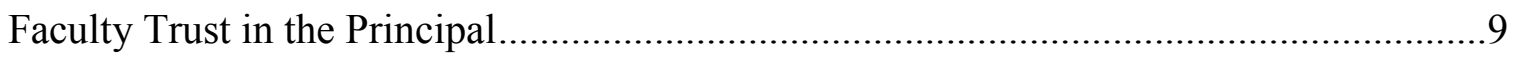

Relationship of Learning-Centered Leadership and Faculty Trust in the Principal ...............11

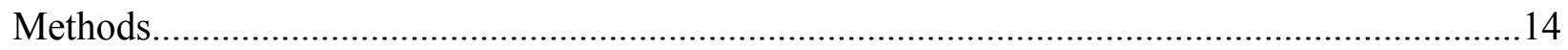

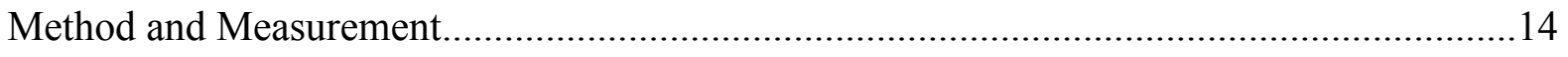

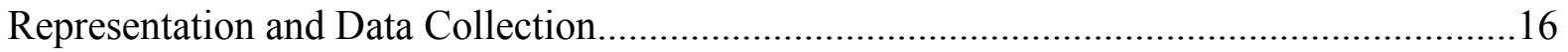

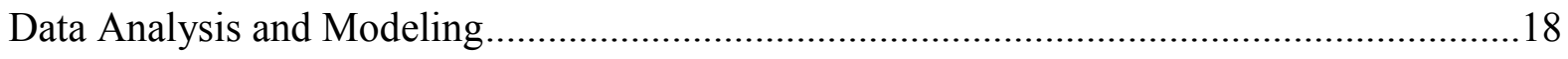

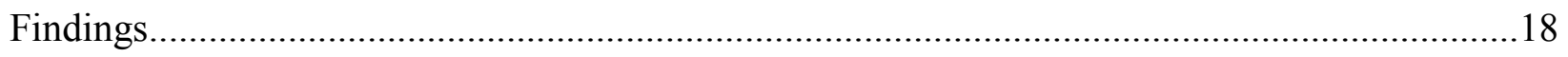

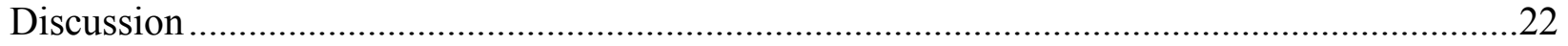

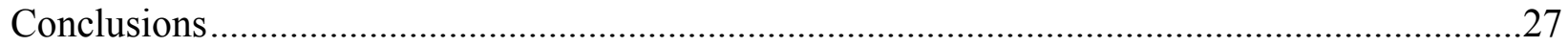

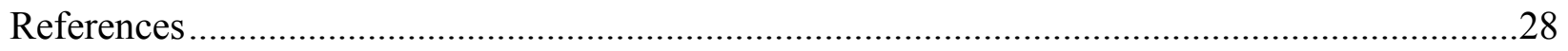

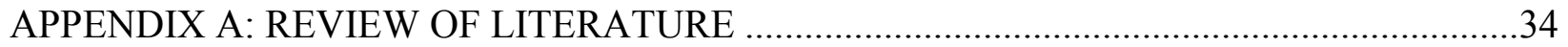

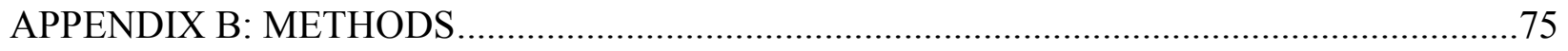

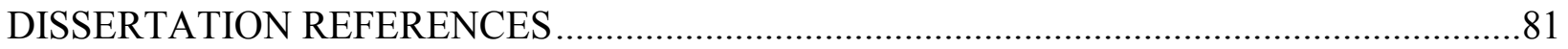




\section{LIST OF TABLES}

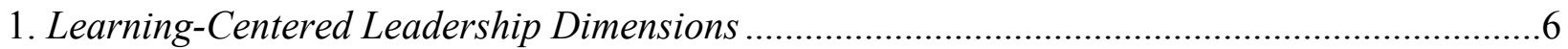

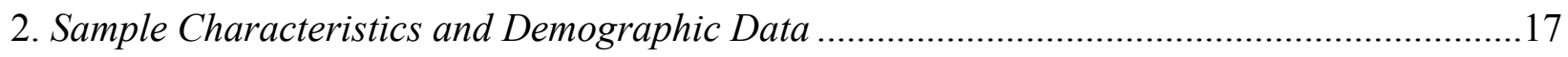

3. Bivariate Analysis Findings .............................................................................................20

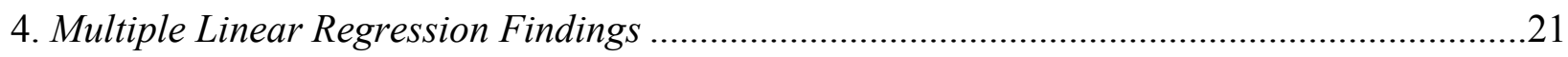




\section{DESCRIPTION OF DISSERATION CONTENT AND STRUCTURE}

Principals are increasingly being held accountable for student achievement outcomes. Their influence on student achievement outcomes is indirect; they are dependent upon other and other variables to achieve those outcomes. Faculty trust in the principal is related to increased student achievement outcomes (Bryk \& Schneider, 2002; Sweetland \& Hoy, 2000; Tschannen-Moran, 2001). This study sought to answer the following research questions:

- What school and principal demographic variables are associated with faculty trust in the principal?

- To what degree is the learning-centered leadership of a principal associated with faculty trust in that principal?

Following a hybrid dissertation model, the manuscript begins by reviewing background information on learning-centered leadership and faculty trust in the principal. Next the manuscript describes the methodology used to gather and analyze the data used in determining the findings of the study. The methods section also includes the findings of the study, a discussion of those findings, and conclusions.

The hybrid dissertation is one of several formats supported in Brigham Young University's McKay School of Education. Unlike a traditional "five chapter" format, the hybrid dissertation focuses on producing a journal-ready manuscript. Consequently, the final dissertation product does not have chapters, rather, it focuses on the presentation of the scholarly manuscript as the centerpiece. Following the manuscript are the manuscript's reference section and the appendices, which include an extended review of literature, a detailed methodological section, and a full reference section.

The targeted journal for this article is the Educational Administration Quarterly (EAQ). EAQ is sponsored and published by the University Council for Educational Administration (UCEA), 
which is the primary professional organization for educational leadership in the United States. The Department of Educational Leadership \& Foundations (EDLF) at Brigham Young University is a full institutional member of UCEA, and EDLF faculty members attend the national conference annually to present research and participate in plenary and business meetings of the organization. Articles submitted to the EAQ are blind reviewed. The manuscript length for submission is 25 to 40 pages. The target audience for the EAQ is composed of both academics and practitioners in educational leadership. 


\section{Introduction}

Recent federal education policy has focused on and expanded accountability for student performance outcomes at the school rather than at the district, teacher, or student level. (Hanushek \& Raymond, 2005). Wiliam (2010) argued, "Differences between students in terms of their educational outcomes, as measured by the tests, should be largely, if not wholly, attributable to differences in the quality of education provided by schools" (p. 110). The logic behind school accountability follows that if school-level policy and quality of education affect education outcomes, then those who determine school policy, make decisions, and affect other variables, the school leaders, should be held accountable for student achievement. Increased pressure and accountability on school leaders for student achievement has its roots in the accountability movement but also in a long-held belief among policy-makers and practitioners throughout U.S. education history that principal leadership affects school performance (Hallinger \& Heck, 1996).

The leadership principals enact to affect student achievement has been conceptualized traditionally as instructional leadership. A more recent conceptualization is leadership for learning or learning-centered leadership (DuFour, 2002; Goldring, Porter, Murphy, Elliot \& Cravens, 2009; Hallinger, 2011; Hallinger \& Heck, 2010; Knapp, Copland, Honig, Plecki, \& Portin, 2010; Knapp, Copland, \& Talbert, 2003; Marks \& Printy, 2003; Murphy, Elliot, Goldring, \& Porter, 2006; Robinson, 2010). During the past several years, as many as six reviews of the empirical research have been conducted to better understand the relationship between school leadership and student outcomes (Bell, Bolam, \& Cubillo, 2003; Leithwood, Harris, \& Hopkins, 2008; Leithwood, Louis, Anderson, \& Wahlstrom, 2004; Marzano, Waters \& McNulty, 2005; Robinson, Lloyd, \& Rowe, 2008; Witziers, Bosker, \& Krüger, 2003). These 
studies have consistently found that principal leadership can indeed affect student achievement, but the effect is indirect. Principal leadership affects other variables that in turn affect student achievement. Knowing that principal leadership indirectly affects student achievement is problematic for school leaders, who are increasingly being held accountable for an outcome they only indirectly affect. Principals must depend on other individuals and other variables for more direct impact on student performance.

School culture and climate variables have been shown to positively affect teacher instructional strategies that have significant positive effects on student learning outcomes (Bryk \& Schneider, 2002; Goddard, Goddard, \& Tschannen-Moran, 2007; Hattie, 2009; Louis \& Wahlstrom, 2011). Consequently, principals seeking to indirectly impact student achievement may choose to influence these variables. Faculty trust in the principal is one such variable; it has been shown to be affected by principal leadership and has been positively associated with student achievement (Bryk \& Schneider, 2002; Sweetland \& Hoy, 2000; Tschannen-Moran, 2001). Bryk and Schneider (2002) indicated,

Relational trust does not directly affect student learning. Rather, trust fosters a set of organizational conditions, some structural and others social-psychological, that make it more conducive for individuals to initiate and sustain the type of activities necessary to affect productivity improvements. (p. 116)

With increased accountability for student achievement outcomes only indirectly affected by their leadership, principals must depend on influencing other individuals to promote and support outcomes for which principals are held responsible. Consequently, principals will benefit from a richer understanding leadership characteristics and qualities affects that affect variables affecting student achievement. This study sought to better understand how principal learning- 
centered leadership is related to a variable associated with student achievement—faculty trust of a principal.

Within the broader relationship of the principal's leadership and faculty's trust in the principal, many inquiries could have been pursued; the specific questions that guided this study were as follows:

- What school and principal demographic variables are associated with faculty trust in the principal?

- To what degree is the learning-centered leadership of a principal associated with faculty trust in that principal?

\section{Review of Literature}

The review of literature introduces the construct of learning-centered leadership. This is followed by a discussion of this leadership as a blend of traditional instructional leadership and transformational learning. This section concludes by explaining the conceptual framework supporting learning-centered leadership. The next section explains and defines faculty trust in the principal for the purposes of this study. Theoretical considerations of trust within an organization, a school, and the trust a faculty places in their principal are then put forth. The review of literature concludes with an explanation of the theoretical justification to hypothesize a relationship between learning-centered leadership and faculty trust in the principal.

\section{Learning-Centered Leadership}

Recent reviews of the empirical research on the relationship between school leadership and student outcomes (Bell et al., 2003; Cotton, 2003; Hallinger, 2003; Leithwood et al., 2006; Leithwood et al., 2004; Marzano et al., 2005; Robinson et al., 2008; Witziers et al., 2003) have considered both the traditional instructional leadership approach that was developed in the 1980's and the transformation leadership model of the 1990's (Hallinger, 2003). Most current 
conceptualizations of instructional leadership include transformational leadership components (Hallinger \& Heck, 2010; Leithwood \& Jantzi, 2005; Marks \& Printy, 2003). Researchers now suggest the term learning-centered leadership for the construct of instructional leadership most recently surfacing in the literature (DuFour, 2002; Goldring et al., 2009; Hallinger, 2011; Murphy et al., 2006; Robinson, 2010), which conceptualizes leadership for learning or learningcentered leadership as a combination of elements from traditional instructional leadership and from transformational leadership.

Beneficial blend. Robinson et al. (2008) conducted a meta-analysis of 27 published studies on the relationship of principal leadership and student outcomes. They found effect sizes three to four times greater for behaviors traditionally associated with instructional leadership than for those of transformational leadership. However, they noted the motivational, collaborative, and interpersonal skills associated with transformational leadership embedded in the construct and practices of instructional leadership. This conceptualization of instructional leadership integrates task and interpersonal leadership behaviors. This finding is supported by additional research considering the impact of transformational leadership compared to instructional leadership (Leithwood \& Jantzi, 2005; Marks \& Printy, 2003).

Consequently, effective instructional leadership is assumed to include behaviors that directly affect instruction but also those transformational behaviors that indirectly impact students' learning by affecting the conditions, people, and factors in schools that encourage their academic achievement. This new conceptualization of instructional leadership considers recent research about ways effective principal leadership may impact student learning. Additionally, Hallinger (2011) stated: 
The fervor of debates over which model offers the greatest leverage for understanding how school leaders contribute to learning has reduced in recent years. Empirical results over a large number of studies have begun to show a fairly consistent pattern of impact, and today, the term "leadership for learning" has come to subsume features of instructional leadership, transformational leadership, and shared leadership. (p. 126)

Several researchers label this construct as leadership for learning, learning-focused leadership, or learning-centered leadership (DuFour, 2002; Knapp, Copland, \& Talbert, 2003; Marks \& Printy, 2003; Hallinger, 2011; Hallinger \& Heck, 2010; Goldring et al. 2009; Murphy et al., 2006; Knapp et al., 2010; Robinson, 2010).

Conceptual foundation. Murphy and his colleagues (2006) in developing a conceptual foundation for learning-centered leadership suggested that two leadership strands have emerged as especially prevalent in high performing schools over the past three decades: (a) leadership for learning or instructionally focused leadership, and (b) change-oriented leadership or transformational leadership. The authors suggested that these two strands are most effective when combined and have conceptualized this combination as learning-centered leadership.

Building on the work of Murphy et al. (2006), Goldring et al. (2009) provided a rationale for their conceptual framework, which became the blueprint for their instrument to assess leadership performance - the Vanderbilt Assessment of Leadership in Education (VAL-ED). This conceptual framework that "is aligned with a research-based definition of educational leadership that is rooted in school improvement ... learning-centered leadership" (p. 4) is based on two dimensions of leadership behaviors identified in Table 1. 
Table 1

Learning Centered Leadership Dimensions (Goldring et al., 2009)

\begin{tabular}{ll}
\hline Core components & Key processes \\
\hline High standards for student achievement & Planning \\
Rigorous curriculum & Implementing \\
Quality instruction & Supporting \\
Culture of learning \& professional behavior & Advocating \\
Connections to external communities & Communicating \\
Systemic performance accountability & Monitoring \\
\hline
\end{tabular}

Core components consist of leadership behaviors that have traditionally been associated with instructional leadership. Key processes are "leadership behaviors, most notably aspects of transformational leadership traditionally associated with processes of leadership that raise organizational members' levels of commitment and shape organizational culture" (p. 5). These core components and key processes are aligned with the Interstate School Leaders Consortium (ISLLC) standards. As with other research findings, Goldring and colleagues (2009) posited that learning-centered leadership behaviors would indirectly influence student success by affecting school variables that can in turn affect student success. This conceptual framework based on a blend of leadership models by Goldring et al. (2009) is similar to the conceptualization reached by Hallinger and Heck (2010); Hallinger (2011); and Knapp et al. (2003).

\section{Faculty Trust in the Principal}

This study hypothesized that faculty trust in the principal is a school-level variable influenced by the learning-centered leadership of a principal. Bryk and Schneider (2002) posited that relational trust does not directly affect student achievement but affects organizational conditions that in turn influence and support the activities and work necessary for improved school and student achievement outcomes. 
Classification, definition and dimensions of trust. Although trust has been defined and classified differently by various disciplines, educational researchers Bryk and Schneider (2002) suggested the term relational trust to describe the trust characteristic of the interpersonal relationships and social interactions within a school. They distinguish relational trust from the organic trust participants unconditionally place in an institution and the contractual trust directed by established rules and expectations. Consideration of other individuals' intentions differentiates relational trust from other types of trust. This study considered the trust relationship between a faculty and the principal as relational trust.

Trust scholars across disciplines that define trust similarly and have consistently noted the multi-dimensional nature of trust (Bryk \& Schneider, 2002; Burke, Sims, Lazzara, \& Salas, 2007; Dirks \& Ferrin, 2002; Hoy \& Tschannen-Moran, 1999; Mayer, Davis, \& Schoorman, 1995; Mishra, 1996; Rousseau, Sitkin, Burt, \& Camerer, 1998). In the literature on trust, one of the most common dimensions of trust is vulnerability. Rousseau and colleagues (1998), in reviewing the literature on trust across multiple disciplines, suggested that, "confident expectations and a willingness to be vulnerable are critical components of all definitions of trust" (p. 394). Mishra (1996) identified trust as willing vulnerability to another party based on the understanding the other party is competent, open, concerned, and reliable.

Reviewing four decades of literature on trust, Hoy and Tschannen-Moran (1999) found 16 different definitions. Synthesizing their findings, they proposed the following: "Trust is an individual's or group's willingness to be vulnerable to another party based on the confidence that the latter party is benevolent, reliable, competent, honest, and open" (p. 189). Benevolence is consideration of the needs of others with a willingness to promote their interests. Reliability describes the consistency and predictability of positive behaviors. Competence refers to the skills 
and abilities needed to complete a task or carry out responsibilities of a position or role. Honesty represents commitment to the truth and to promises made to another. Finally, openness denotes transparency in making decisions and sharing of relevant information and control. These facets reflect the literature regarding the multi-dimensional nature of trust.

In summary, trust involves a willingness of one party to accept vulnerability and risk if the other party is perceived to have certain characteristics. For the purposes of this study, trust was conceptualized as relational or interpersonal trust of a faculty for its principal. Additionally, this study utilized the trust definition of Hoy and Tschannen-Moran (1999) definition of trust of vulnerability based on the perception of the other party's benevolence, reliability, competence, honesty, and openness.

Trust within organizations. Organizations consist of interdependent individuals working to affect organizational outcomes. Trust among these individuals has been found to have positive, significant effects on individual as well as organizational outcomes. In a review of the literature on trust in organizations, Kramer (1999) summarized the benefits as reducing transaction costs, increasing spontaneous sociality among organizational members, and facilitating appropriate forms of deference to organizational authorities.

Dirks and Ferrin (2001) reviewed the research on the role of trust in organizational outcomes finding significant positive effects of trust on organizational members' citizenship behaviors and individual performance. They found further supporting evidence of the relationship of trust and workers' attitude, job satisfaction, acceptance of information, and workplace perceptions.

Megan Tschannen-Moran (2001) suggested several outcomes for an organization with a climate of trust. First, members with a high degree of trust are more open and share more 
accurate and relevant information. Second, they are willing to do more than the minimal expectations of their job requirements. Finally, members of high-trust organizations feel more comfortable and focus more on organizational goals than on self-protection.

Trust in schools. Schools are social institutions that depend on existing interpersonal relationships and daily exchanges within the organization to achieve organizational outcomes. Given the positive relationship of trust and organizational outcomes, educational researchers have considered the relationship of trust and positive educational outcomes. Tschannen-Moran (2004) referred to trust as a both at glue and a lubricantd to trust Arguing the need for trust in schools, Louis and Wahlstrom (2011) stated, (2011) stated1) statedust in schools, Louis and Wahlstromty can endure without trustin s. 55). Bryk and Schneider (2002) stated that hat d that and Wahlstrom (s have considered the relationship of trust and positare willing to do more than thcision making, enhanced social support for innovation, more efficient social control of adults002) stated that tionauthority adults002) stated that tion, more efficient 22).

Research has shown a direct relationship between trust levels in schools and student achievement (Bryk \& Schneider, 2002; Goddard, Salloum, \& Berebitsky, 2009). In addition to direct effects on student achievement, research has also established significant positive relationships between trust levels in a school and other variables that affect student achievement such as willingness to innovate (Louis, 2007), collaboration and shared decisionmaking (Tschannen-Moran, 2001), teacher efficacy (Goddard, Hoy, \& Hoy, 2000), and school mindfulness (Hoy, Gage, \& Tarter, 2006).

Faculty trust in the principal. Although school trust research has focused on a number of interpersonal relationships that exist in a school (e.g., faculty trust in students and parents, faculty trust in colleagues, parent trust in faculty), faculty trust in the principal was chosen as the 
focus of this study. Bryk and Schneider (2002) suggested that principals affect relational trust when they "acknowledge the vulnerabilities of others, actively listen to their concerns, and eschew arbitrary actions" (p. 137). When they add to these behaviors, a compelling vision of improvement and actions consistent with that vision, their integrity is established. These purposeful actions in the context of competent management of daily operations lead to conditions that foster faculty trust. In summary, faculty trust in the principal is more likely when principals are competent in their role and responsibilities, create a vision for improvement, demonstrate integrity in their actions, and show concern for others in the process.

In research on faculty trust in the principal, specific principal behaviors have surfaced as positively associated with this trust. Principals may establish enabling structures which lead to greater faculty trust (Hoy \& Sweetland, 2001). Tarter, Bliss, and Hoy (1989) found a positive relationship between an open organizational climate and faculty trust. Moye, Henkin, and Egley (2005) found higher levels of trust for principals who empower teachers. Tschannen-Moran (2003) considered the relationship between trust and organizational citizenship, finding the strongest positive relationship between a principal's transformational leadership behaviors and a faculty's trust. This finding was supported by the research of Hoy, Smith, and Sweetland (2002) who determined the collegial leadership of a principal has a strong positive relationship with faculty trust. They argued, "Leaders who are open with teachers, treat them as colleagues, are friendly and considerate, and ... reasonable standards are not only accepted by their teachers but are rewarded with their trust" (p. 47).

In summary, the research on faculty trust in the principal demonstrated two consistent findings. First, principals' behavior has a significant positive direct effect directly on their faculty trust along with indirect effects on other positive school outcomes. Second, the behaviors 
associated with higher levels of faculty trust in the principal represent the facets or components of trust as discussed: willingness to be vulnerable to the actions of the principal based on confidence that the principal is benevolent, reliable, competent, honest, and open (TschannenMoran, 2004).

\section{Relationship of Learning-Centered Leadership and Faculty Trust in the Principal}

This study hypothesized a relationship between principals' learning-centered leadership of the faculty trust they receive. Previous sections separated the conceptualizations of learningcentered leadership and faculty trust in their principal; this section discusses the theoretical relationship between the concepts including justification for suggesting a relationship between principal learning-centered leadership and faculty trust in the principal.

As noted previously, leadership is indirectly related to student achievement outcomes; it affects other variables. In building a knowledge base for effective educational leadership for the Wallace Foundation-funded Learning from Leadership project, Leithwood et al. (2004) reported three general findings from their research on the influence of school leadership on student achievement. First, researchers found that the influence was indirect through other people and features of the organization. Second, the research suggested who those individuals and what those organizational features are. Third, the authors asserted more research needed to be done to determine how school leadership influences these individuals and organizational features. Faculty trust has been established as an organizational feature related to student achievement (Bryk \& Schneider, 2002). Thus this study suggests that faculty trust in the principal is one organizational variable influenced by principal leadership.

Another theoretical argument supporting the hypothesized relationship was learningcentered leadership includes both traditional instructional leadership behaviors focused on 
instructional improvement variables and transformational leadership behaviors that address task and relationship variables. Leadership in organizations such as schools is focused on improving employee (teacher) performance. Improved teacher performance should improve student performance-achievement. Teachers' beliefs, motivations, skills, knowledge, and working conditions affect their performance. Faculty trust in the principal is one measure of teachers' beliefs about their working relationships and an aspect of their working conditions. Consequently, this study assumed that learning-centered leadership, conceptualized as both traditional instructional leadership behaviors and transformational leadership behaviors, would influence teachers' skills and knowledge as well as beliefs, motivations, and working conditions. This study further assumed faculty trust in the principal to be a measure of these variables.

An additional theoretical justification for the relationship considers both the antecedents of relational trust and the facets of trust. Bryk and Schneider (2002) suggested that the development of relational trust in schools context includes discerning the intentions of others to fulfill obligations and expectations associated with the shared task of educating students. They established four criteria for discerning relational trust in a school setting: (a) interpersonal respect understanding the importance of others' roles in education students; (b) role competence, the ability to do one's job well; (c) personal regard for others, concern for their well-being; and (d) personal integrity, honesty in communication, consistency between words and behavior. Clearly these criteria for discernment are consistent with Hoy and Tschannen-Moran's (1999) previously explained five facets of trust: benevolence, reliability, competence, openness, and honesty. Consequently, these studies suggested the antecedents of relational trust to be competence, benevolence, reliability, openness, and integrity, which are theoretically congruent with the core components and key process behaviors associated with learning-centered 
leadership. Thus in theory principals who engage in the behaviors of learning-centered leadership are practicing the behaviors that are related to relational trust. Learning-centered leadership demonstrates competence, reliability, benevolence, openness, and integrity—the criteria of trust discernment.

The theoretical argument for an assumed relationship between learning-centered leadership and faculty trust in the principal justifies further empirical study of that relationship. While this study assumed that the learning-centered leadership of a principal was related to faculty trust in the principal, the researchers considered it plausible that other variables also affect this trust. Thus other possible contributing variables were considered including organizational variables such as the school level (e.g., elementary, junior high, or high school), school size (i.e., number of full-time teachers), percentage of female faculty, median years of faculty experience, percentage of minority students, and percentage of students at the school receiving free or reduced-priced lunch. A final organizational variable that warranted consideration was school achievement level. The focus of this study was not on student achievement; however, the perception by the faculty of the achievement level of the school as a whole, as measured by a school grade, may affect the trust a faculty places in the principal.

In addition to these organizational variables, personal or relationship variables could also affect faculty trust in the principal. Personal characteristics of the principal such as age, gender, and number of years in administration were considered. Faculty trust in a principal might also be related to the number of years the faculty of a school and the principal have worked together. Thus while researchers hypothesized that the learning-centered leadership of a principal would account for much of the variation in faculty trust levels, they investigated other organizational and relationship variables that could account for some of that variation as well. 


\section{Methods}

\section{Method and Measurement}

This study was a quantitative study limited to teachers in the elementary, junior high, and high schools of one large school district in the Rocky Mountain region of the United States. The study proposed to determine (a) which school and principal demographic variables were associated and (b) to what degree the learning-centered leadership of a principal was associated with faculty trust in the principals for this district. A faculty trust score for each school principal served as the dependent or outcome variable. The overall learning-centered leadership score for each school principal was the main independent or explanatory variable, and other school and principal demographic variables were analyzed as independent or control variables.

The learning-centered leadership of the principals was measured using the Vanderbilt Assessment of Leadership in Education (VAL-ED) instrument developed through Vanderbilt University and the Wallace Foundation. The VAL-ED instrument focuses on specific principal behaviors associated with learning-centered leadership. The developers identified six core components of school performance and six key processes of school leadership (See Table 1) aspects of leadership that combine to form the construct of learning-centered leadership measured by the instrument. The multi-stage developmental process of the instrument included cognitive labs, pilot tests, and field tests. The field trial sample consisted of more than 270 schools and over 8,000 individual evaluations, with 218 schools having complete sets of responses. The sample included elementary, middle, and high schools from all regions of the United States (Porter, Polikoff, Goldring, Murphy, Elliott, \& May, 2010).

The VAL-ED instrument produces a mean score based on the six core components and a mean score based on the six key processes for each principal. The total effectiveness score is an 
average of these two scores. Teachers indicated their ranking of their principal on each of the six core process and six key components using a 5-point Likert scale ranging from ineffective to outstandingly effective. In addition to the score of learning-centered leadership for each principal, the following control or demographic principal variables were included in the study data: age, gender, mean years of administrative experience, and mean number of years as the principal of the faculty responding to the survey.

The outcome variable in this study, faculty trust in the principal, was measured using the Omnibus T-Scale developed by Hoy and Tschannen-Moran (2003). The instrument measures multiple dimensions of faculty trust: in the principal, in colleagues, and in clients (students and parents). The full instrument consists of 26 Likert items that include all of the subscales. However, the data for this study were gathered using the eight items associated with the subscale of faculty trust in the principal. Teachers indicated their level of agreement on a 6-point Likert scale from strongly disagree to strongly agree for each item.

The Omnibus T-Scale provided an aggregate mean score of faculty trust for each principal in the study. Additional faculty and school demographic data were gathered: school level, school size, percentage of female faculty, mean years of faculty experience, percentage of students from minority backgrounds, percentage of students on free and reduced-price lunch, and the school academic grade for the previous year.

The unit of analysis of this study was at the school or principal level. While the principals referred to or responded about in the two data sets were the same and the respondents in each data set were from the same school, the individual item responses from the VAL-ED behavior measurement were not specifically tied to the same individual item responses from the Omnibus T-Scale. The data for both sets were gathered in the spring of the 2012-2013 and 2013-2014 
school years. The school and principal demographic data were gathered from the school district database at the time of the surveys.

\section{Representation and Data Collection Process}

The data collection process for this study targeted the principals and faculty members of all the traditional schools in a large suburban school district in the Rocky Mountain region of the United States. All non-specialty schools in the district were targeted for participation in the study. The actual level of participation was as follows: 40 elementary schools, 11 junior high schools, and eight high schools. Teachers at each of the schools completed the behavior and trust survey items concerning their principal. Table 2 gives an overview of the data generated from the surveys and the district database. 
Table 2

Sample Characteristics and Demographic Data

\begin{tabular}{|c|c|c|c|c|}
\hline School characteristics & Elementary & Junior high & High school & Totals \\
\hline Number of schools & 40 & 11 & 8 & 59 \\
\hline Mean school size - full time teachers & 29 & 40 & 61 & 35 \\
\hline Percent of faculty female & $90 \%$ & $60 \%$ & $51 \%$ & $79 \%$ \\
\hline Mean years of experience & 10 & 11 & 12 & 10 \\
\hline Percentage of minority students & $17 \%$ & $17 \%$ & $15 \%$ & $17 \%$ \\
\hline Percentage of poverty students & $35 \%$ & $29 \%$ & $23 \%$ & $32 \%$ \\
\hline School grade_-number of $A$ grades & 7 & 2 & 0 & 9 \\
\hline School grade_-number of $B$ grades & 23 & 9 & 7 & 39 \\
\hline School grade_-number of $C$ grades & 10 & 0 & 1 & 11 \\
\hline
\end{tabular}

Principal characteristics Elementary Junior high High school Totals

\begin{tabular}{lcccc}
\hline Mean age & 48 & 44 & 45 & 46 \\
Gender_number of male & 26 & 11 & 7 & 34 \\
Gender - number of female & 14 & 0 & 1 & 15 \\
Mean years in administration & 7.95 & 6.18 & 7.37 & 7.54 \\
Mean years with faculty & 3.73 & 3.10 & 2.61 & 3.46 \\
Mean principal leadership score-5 point & 3.96 & 3.95 & 3.79 & 3.94 \\
scale & & & & 5.11 \\
Mean faculty trust in principal score-6 & 5.14 & 5.24 & 4.82 & \\
point scale & & &
\end{tabular}




\section{Data Analysis and Modeling}

After determining the overall learning-centered leadership score and faculty trust score, bivariate analyses explored possible relationships between faculty trust in the principal and the school and principal demographic variables. The analysis included principal learning-centered leadership as one of the variables associated with the principal. These bivariate analyses assessed if faculty trust in the principal was related to any of the variables without adjusting for the influence of any other variable.

The next level of analysis consisted of building models of trust using multiple linear regressions. These analyses explored the significance of the relationship between principal learning-centered leadership and faculty trust in the principal while adjusting for the influence of principal and school characteristics on that trust. The purpose of this analysis was to determine the model that best described faculty trust in the principal. The multiple linear regressions considered the demographic or characteristic variables individually to determine their relationship with faculty trust in the principal and their interaction with principal learningcentered leadership within the context of the learning-centered leadership and faculty trust in the principal.

\section{Findings}

The focus of this study was to determine (a) what principal and school demographic variables are associated with faculty trust in the principal, and (b) to what degree principal learning-centered leadership is associated with that trust. The analysis process included exploring these relationships through bivariate and multiple linear regression analyses.

Table 3 illustrates the findings from the bivariate analyses done on the variables listed and faculty trust in the principal. The only school and principal variables shown to have a 
significant relationship with faculty trust in the principal were school level at the high school level, specifically at the elementary and high school levels and principal learning centered leadership. 
Table 3

Bivariate Analysis Findings

School predictor variables

Coef SE

School type***

Elementary

$5.14 \quad .063$

Junior high

$5.24 \quad .135$

High school

4.92

.153

School grade***

$A$ grade

$5.27 \quad .136$

$B$ grade

5.10

.151

$C$ grade

$5.04 \quad .184$

School size

$-.005 \quad .004$

Percentage of faculty female

$.002 \quad .003$

Years of experience

$-.015 \quad .022$

Percentage of minority students

$.000 \quad .004$

Percentage of poverty students

$.002 \quad .003$

Principal predictor variables

Coef

SE

Gender

Female

5.02

.122

Male

$5.15 \quad .105$

Age

$-.002 \quad .006$

Number of years in administration

$.17 \quad .010$

Number of years with faculty

.04

.033

Principal learning-centered leadership $* * *$

.67

.172

${ }^{*} p<.05 .{ }^{*} * p<.01 . * * * p<.001$. 
Following the bivariate analyses, multiple linear regression analyses were performed.

Several multiple linear regression models were assessed in order to determine the model with the best fit. A backward elimination strategy was used and all two-way interactions between principal learning-centered leadership and the other principal and school characteristic variables were considered. The terms in the best-fitting model are listed in Table 4 .

Table 4

Multiple Linear Regression Findings

\begin{tabular}{lcc} 
Variable & Coef & SE \\
\hline Principal learning-centered leadership*** & 1.11 & .17 \\
Principal learning-centered leadership and school & 1.20 & .40 \\
grade $C$ interaction** & & \\
School grade-C $C^{* *}$ & -4.76 & 1.58 \\
Principal gender-female*** & -.32 & .17 \\
${ }^{*} p<.05 .{ }^{* *} p<.01 .{ }^{* * *} p<.001$. & &
\end{tabular}

Principal learning-centered leadership was significantly and positively related to faculty trust in the principal; principals in this study with higher learning-centered leadership scores had higher faculty trust in principal scores. The $\mathrm{R}^{2}$ was .609 , indicating that approximately $60 \%$ of the variance in faculty trust in the principal was attributable to the principal's learning-centered leadership, school grade, and principal gender.

Additionally, for the principals in this study every unit increase in perceived learningcentered leadership scores resulted in a 1.11 increase in faculty trust in the principal scores. The significance of the relationship was even stronger in schools with a $C$ academic achievement grade, which is assigned by the State Office of Education and is reflective of lower student achievement scores. In $C$ graded schools, every unit increase in principal learning-centered leadership scores resulted in a 2.31 increase in faculty trust in the principal scores. Thus, the slope for $C$ schools is twice that of $A$ and $B$ schools. For this study, principal learning-centered 
leadership is related to faculty trust in the principal and has an even stronger relationship in those schools determined to be lower in academic achievement.

Another finding was that after adjusting for principal learning-centered leadership and a $C$ school grade, principal gender female was significantly associated with faculty trust in the principals. Once learning-centered leadership was considered, the findings indicated females had lower average faculty trust scores than male principals. This relationship was not evidenced in the findings from the bivariate analysis, but became evident once the relationship was adjusted for the learning-centered leadership variable. Conversely, the variable of school type that was significant in the findings of the bivariate analysis was no longer significant when the model adjusted for the learning-centered leadership variable. Lastly, the variables associated with school grades $A$ and $B$ had a similar influence on faculty trust in the multiple linear regression model, so the final model combined them.

Another important finding of this study was what principal and school variables are not related to faculty trust in the principal once principal learning-centered leadership is considered. For the principal, the variables age, time in administration, and time spent with a faculty do not have a significant relationship with faculty trust in the principal. Neither do the school variables type, size, years of faculty experience, the percentage of female faculty members, nor minority or poverty students at the school.

\section{Discussion}

In the report for the Wallace Foundation on How Leadership Influences Student Learning, Leithwood and colleagues (2004) make two important claims based on their 10-year study and review of the literature. They claim "Leadership is second only to classroom instruction among all school-related factors that contribute to what students learn at school" and 
"Leadership effects are usually largest where and when they are needed most" (p. 5). In essence, leadership matters, and it matters most in the schools with lower achievement levels. Other research has also shown that leadership matters, but the process of making the leadership influence matter is indirect (Robinson et al., 2008; Witziers et al., 2003). Leadership influences other variables that influence student outcomes. One of those variables influenced by principal leadership that is related to student achievement is faculty trust in the principal. High levels of faculty trust in the principal are associated with higher levels of student achievement (Bryk \& Schneider, 2002; Sweetland \& Hoy, 2000; Tschannen-Moran, 2001).

The results of this study are consistent with these research findings. For the schools in this study, principal learning-centered leadership mattered. It is significantly related to a variable shown to be associated with higher levels of student achievement. It accounted for $60 \%$ of the variance in faculty trust in the principal trust scores. Each unit of increase in learning-centered leadership increased that faculty trust more than one point on a five-point scale. That leadership mattered even more in schools that needed it most. Principal learning-centered leadership had twice the effect on faculty trust in $C$ graded schools. Every point increase in the learningcentered leadership garnered a two-point increase in the level of faculty trust.

A school's grade was a state mandated rating of a school based on (a) the proficiency of its students in language arts, mathematics, and science as measured by statewide assessments; (b) learning gains of its students on the above statewide assessments; and (c) graduation rate and student performance on a college admissions test for high schools. Schools were awarded points based on these measures, and the letter grade was based on the percentage resulting when the score was divided by the maximum number of points the school could earn. Letter grades were assigned as follows: $100-80 \%=A, 79-70 \%=B ; 69-60 \%=C, 59-50 \%=D, 49 \%$ or less $=F$. 
Furthermore, state code required the State Board of Education to develop a report card for each school including (a) the school's grade and (b) the school's percentage of the maximum number of points that could be earned, with specific ranking on the various categories that determined the grade. The school grade for the previous school year was made public in the early fall of each school year. The school grade used for this study was the grade assigned for the year the surveys were taken. In this study, leadership mattered even more in lower performing or $C$ graded schools.

The findings of this study indicated what degree principal learning-centered leadership was related to the faculty's trust of their principal. The study also determined what school and principal demographic variables were related to faculty trust in the principal. With the exception of principal learning-centered leadership, principal gender, and a $C$ school grade, no other variables had a significant relationship with faculty trust in the principal. This trust was not related to the school variables of type, size, faculty experience, female faculty percentage, or minority and poverty student percentages. Neither was this trusted related to principal demographic variables of age, years of experience, or years with faculty.

These findings are consistent with other leadership and trust research. Multiple research studies have indicated that faculty trust in the principal is related to principal leadership and not other variables (Hoy et al., 2002; Hoy \& Sweetland, 2001; Moye et al., 2005; Tarter et al., 1989; Tschannen-Moran, 2003). Principal leadership varied in its conceptualization in these studies: enabling leadership, supportive and non-directive leadership, transformational leadership, and collegial leadership. Consequently, this study supports the understanding that principals build trust through their leadership not through the other variables in this study. Principals should take 
confidence knowing that a variable over which they have considerable control, leadership, affects trust, not variables over which they have little or no control.

In their study on trust in schools, Bryk and Schneider (2002) discussed the reciprocal vulnerabilities inherent in the principal-teacher relationship. This relationship is typically hierarchical because of the lower-status nature of teachers and the positional power principals exercise over them. In this relationship, teachers risk being treated unfairly or being submitted to work conditions that do not enhance their effectiveness or their students' achievement. They must depend on their principal to support their efforts. Principals risk having unproductive teachers who may actually undermine the work of improving student achievement. Principals depend on teachers to improve instructional effectiveness and student achievement. Thus principals and teachers both face risks; because they are interdependent; they are vulnerable. Relations of trust can lessen these vulnerabilities. Principals can affect the level of trust and thus reduce vulnerability through their interactions with and leadership towards teachers. This study provided empirical evidence that principal learning-centered leadership is a type of leadership that is associated with faculty trust in the principal.

Developing relational trust was a capability included by Robinson (2010) in her preliminary model of the capabilities necessary for school leaders to effectively engage in instructional leadership. In essence, learning-centered leadership includes both leadership behaviors that directly affect instruction and leadership capabilities that create conditions for those leadership behaviors to be more effective. For example, a principal engaged in learningcentered leadership would enact a leadership behavior focused on improving instruction such as setting high standards for student achievement. However, focusing on this leadership behavior alone would not be as effective as combining this leadership behavior with the capability of 
building relational trust. As a school faculty trusted in its leader's competency, reliability, benevolence, and honesty in setting high standards, they would be more likely to engage in the work necessary to achieve those high standards of student learning. Learning-centered leadership affects learning because it creates the conditions necessary to increase the effectiveness of leadership behaviors directly associated with improving learning. Faculty trust is the principal is one of the necessary conditions.

One additional finding in this study warrants discussion. In the final model that considered the effect of principal-learning centered behavior and principal gender on faculty trust in the principal, the demographic variable, principals being female, was negatively associated with faculty trust in the principal. Principal gender and faculty trust in the principal did not demonstrate a significant relationship in the bivariate analysis. However, in the multiple linear regression model this negative relationship was apparent. Male principals evidenced a slight increase in trust scores when leadership was considered. The cause of this finding was not empirically determined. A theoretical assumption might be that teachers are sexist towards female principals. However, other more plausible explanations might be related to the ratio of female teachers to female principals and male principals in the study. It might also be related to the manner in which female principals enact learning-centered leadership behaviors such as monitoring which can be associated with negative actions such as checking on someone or micromanaging tasks (Costa \& Anderson, 2011). Further empirical research is suggested to explore this finding and determine if it is replicable or simply was unique to this study. 


\section{Conclusions}

School principals are being held accountable for student achievement outcomes; however, research on principal leadership has shown a significant but only indirect effect on student achievement. Principals influence student achievement by affecting other variables that in turn affect student achievement. Consequently, principals are being held accountable for an outcome they indirectly affect. Therefore, they would benefit from a better understanding of how their behavior affects school climate and conditions variables associated with increased student achievement. Faculty trust in the principal is one of those variables related to student achievement over which principals have influence through their leadership. This study offers empirical evidence that principal learning-centered behavior was significantly and positively related to faculty trust in the principal. This finding increases our understanding of the relationship between principal leadership, faculty trust in the principal, and other school variables. Principals who wish to positively affect the trust their faculty places in them would do well to engage in those behaviors associated with learning-centered leadership. 


\section{References}

Bell, L., Bolam, R., \& Cubillo, L. (2003). A systematic review of the impact of school leadership and management on student outcomes. EPPI-Centre, Social Science Research Unit, Institute of Education: University of London.

Bryk, A., \& Schneider, B. (2002). Trust in schools: A core resource for improvement. New York, NY: Russell Sage Foundation.

Burke, C. S., Sims, D. E., Lazzara, E. H., \& Salas, E. (2007). Trust in leadership: A multi-review and integration. The Leadership Quarterly, 18(6), 606-632.

Cotton, K. (2003). Principals and student achievement: What the research says. Alexandria, VA: Association for Supervision and Curriculum Development.

Dirks, K. T., \& Ferrin, D. L. (2001). The role of trust in organizational settings. Organization Science, 12(4), 450-467.

Dirks, K. T., \& Ferrin, D. L. (2002). Trust in leadership: Meta-analytic findings and implications for research and practice. Journal of Applied Psychology, 87(4), 611-628.

DuFour, R. (2002). The learning-centered principal. Educational Leadership, 59(8), 12-15.

Goddard, R. D., Hoy, W. K., \& Hoy, A. W. (2000). Collective teacher efficacy: Its meaning, measure, and impact on student achievement. American Educational Research Journal, $37(2), 479$.

Goddard, R. D., Salloum, S. J., \& Berebitsky, D. (2009). Trust as a mediator of the realtionships between poverty, racial composition, and academic achievement: Evidence from Michigan's public elementary schools. Educational Administration Quarterly, 45(2), 292-311. 
Goddard, Y. L., Goddard, R. D., \& Tschannen-Moran, M. (2007). A theoretical and empirical investigation of teacher collaboration for school improvement and student achievement in public elementary schools. Teachers College Record, 109(4), 877-896.

Goldring, E., Porter, A., Murphy, J., Elliot, S. N., \& Cravens, X. C. (2009). Assessing learningcentered leadership: Connections to research, professional standards, and current practices. Leadership and Policy in Schools, 8(1), 1-36.

Hallinger, P. (2003). Leading educational change: Reflections on the practice of instructional and transformational leadership. Cambridge Journal of Education, 33(3), 329-352.

Hallinger, P. (2011). A review of three decades of doctoral studies using the Principal Instructional Management Rating Scale: A lens on methodological progress in educational leadership. Educational Administration Quarterly, 47(2), 271-306.

Hallinger, P., \& Heck, R. H. (1996). Reassessing the principal's role in school effectiveness: A review of empirical research, 1980-1995. Educational Administration Quarterly, 32(1), $5-44$.

Hallinger, P., \& Heck, R. H. (2010). Leadership for learning: Does collaborative leadership make a difference in school improvement? Educational Management Administration \& Leadership, 38(6), 654-678.

Hanushek, E. A., \& Raymond, M. E. (2005). Does school accountability lead to improved student performance? Journal of Policy Analysis and Management, 24(2), 297-327.

Hattie, J. (2009). Visible learning: A synthesis of 800+ meta-analyses on achievement. New York, NY: Routledge. 
Hoy, W. K., Gage, C. Q. III, \& Tarter, J.C. (2006). School mindfulness and faculty trust: Necessary conditions for each other? Educational Administration Quarterly, 42(2), 236255.

Hoy, W. K., Smith, P. A., \& Sweetland, S. R. (2002). The development of the organizational climate index for high schools: Its measure and relationship to faculty trust. The High School Journal, 86(2), 38-49.

Hoy, W. K., \& Sweetland, S. R. (2001). Designing better schools: The meaning and measure of enabling school structures. Educational Administration Quarterly, 37(3), 296-321.

Hoy, W. K., \& Tschannen-Moran, M. (1999). Five faces of trust: An empirical confirmation in urban elementary schools. Journal of School Leadership, 9, 184-208.

Hoy, W. K. \& Tschannen-Moran, M. (2003). The conceptualization and measurement of faculty trust in schools: The omnibus T-scale. In W.K. Hoy \& C.G. Miskel, Studies in Leading and Organizing Schools (pp. 181-208). Greenwich, CT: Information Age Publishing.

Knapp, M. S., Copland, M. A., Honig, M. I., Plecki, M. L., \& Portin, B. S. (2010). Learningfocused leadership and leadership support: Meaning and practice in urban systems. Seattle: University of Washington, Center for the Study of Teaching \& Policy.

Knapp, M. S., Copland, M. A., \& Talbert, J. E. (2003). Leading for learning: Reflective tools for school and district leaders. Seattle: University of Washigton, Center for the Study of Teaching and Policy.

Kramer, R. M. (1999). Trust and distrust in organizations: Emerging perspectives, enduring questions. Annual Review of Psychology, 50(1), 569-598.

Leithwood, K., Harris, A., \& Hopkins, D. (2008). Seven strong claims about successful school leadership. School Leadership and Management, 28(1). 27-42. 
Leithwood, K., \& Jantzi, D. (2005). A review of transformational school leadership research 1996-2005. Leadership and Policy in Schools, 4(3), 177-199.

Leithwood, K., Louis, K. S., Anderson, S., \& Wahlstrom, K. (2004). How leadership influences student learning: A review of research for the Learning from Leadership project. New York, NY: The Wallace Foundation.

Louis, K.S. (2007). Trust and improvement in schools. Journal of Educational Change, 8(1), 124.

Louis, K. S., \& Wahlstrom, K. (2011). Principals as cultural leaders: Principals shape the culture in positive ways when they share leadership and take responsibility for shaping classroom improvements. Phi Delta Kappan, 92(5), 52-56.

Marks, H. M., \& Printy, S. M. (2003). Principal leadership and school performance: An integration of transformational and instructional leadership. Educational Administration Quarterly, 39(3), 370-397.

Marzano, R. J., Waters, T., \& McNulty, B. A. (2005). School leadership that works: From research to results. Alexandria, VA: Association for Supervision and Curriculum Development.

Mayer, R. C., Davis, J. H., \& Schoorman, D. F. (1995). An integrative model of organizational trust. Academy of Management Review, 20(3), 709-734.

Mishra, A. K. (1996). Organizational responses to crisis: The centrality of trust. In R. M. Kramer \& T. Tyler (Eds.), Trust in Organizations (pp. 261-287). Newbury Park, CA: Sage.

Moye, M. J., Henkin, A. B., \& Egley, R. J. (2005). Teacher-principal relationships: Exploring linkages between empowerment and interpersonal trust. Journal of Educational Administration, 43(3), 260-277. 
Murphy, J., Elliott, S. N., Goldring, E., \& Porter, A. C. (2008). Learning-Centered leadership: A Conceptual Foundation. New York, NY: The Wallace Foundation.

Porter, A. C., Polikoff, M. S., Goldring, E. B., Murphy, J., Elliott, S. N., \& May, H. (2010). Investigating the validity and reliability of the Vanderbilt assessment of leadership in education. The Elementary School Journal, 111(2), 282-313.

Robinson, V. M. (2010). From instructional leadership to leadership capabilities: Empirical findings and methodological challenges. Leadership and Policy in Schools, 9(1), 1-26.

Robinson, V. M., Lloyd, C. A., \& Rowe, K. J. (2008). The impact of leadership on student outcomes: An analysis of the differential effects of leadership types. Educational Administration Quarterly, 44(5), 635-674.

Rousseau, D. M., Sitkin, S. B., Burt, R. S., \& Camerer, C. (1998). Not so different after all: A cross-discipline view of trust. Academy of Management Review, 23(3), 393-404.

Sweetland, S. R., \& Hoy, W. K. (2000). School characteristics and educational outcomes: Toward an organizational model of student achievement in middle schools. Educational Administration Quarterly, 36(5), 703-729.

Tarter, J. C., Bliss, J. R., \& Hoy, W. K. (1989). School characteristics and faculty trust in secondary schools. Educational Administration Quarterly, 25(3), 294-308.

Tschannen-Moran, M. (2001). Collaboration and the need for trust. Journal of Educational Administration, 39(4), 308-331.

Tschannen-Moran, M. (2003). Fostering organizational citizenship in schools. Studies in Leading and Organizing Schools (pp. 157-179). Greenwich, CT: Information Age Publishing.

Tschannen-Moran, M. (2004). Trust matters: Leadership for successful schools. San Francisco, CA: Jossey-Bass Publishers. 
Wiliam, D. (2010). Standardized testing and school accountability. Educational Psychologist, 45(2), 107-122.

Witziers, B., Bosker, R. J., \& Kruger, M. L. (2003). Educational leadership and student achievement: The elusive search for an association. Educational Administration Quarterly, 39(3), 398-425. 


\section{APPENDIX A: REVIEW OF LITERATURE \\ Accountability and Instructional Leadership}

Although accountability systems were evident in several states prior the passage of the federal No Child Left Behind (NCLB) legislation in 2002 (Hanushek \& Raymond, 2005), NCLB has become the most famous and far reaching accountability system to date. This law certainly placed American public education in the age of accountability. The NCLB legislation is based on the logic and assumptions supporting school accountability efforts and policies. Wiliam (2010) explained the assumption accordingly "Differences between students in terms of their educational outcomes, as measured by the tests, should be largely, if not wholly, attributable to differences in the quality of education provided by schools" (p. 110). This assumption coupled with the long standing belief among the general public and politicians that school leaders impact the quality of education provided by schools has led to increased school leader accountability for student educational outcomes (Robinson, 2010). However, this belief pre-dated the age of accountability.

The effective schools research that began in the 1970's (Hallinger \& Heck, 1996) provided empirical evidence to support the belief. This research was in response to the Coleman (1968) report that concluded family background was the determining factor in school and student success. The research known as the effective school studies sought to find successful schools particularly among the poor or those that lacked the demographic or family variables Coleman (1968) suggested contributed to student success. Both Edmonds (1979) and Brookover and Lezotte (1979) found that schools do in fact influence enough variables affect student achievement. These researchers noted the role of the school leader in effective schools. Brookover and Lezotte (1979) examined eight Michigan public schools. Changes in fourth grade 
math and reading scores over a two-year period identified six as improving and two as declining. Teachers and staff members completed questionnaires and interviews by researchers. One of the findings relevant to this study was that "There seems to be a clear difference in the principal's role in the improving and declining schools. In the improving school, the principal is more likely to be an instructional leader, is more likely to be assertive in his or her instructional leader role..." (p. 5). Weber (1971) studied four effective inner-city schools that were particularly successful compared to national norms in teaching poor children reading. He found positive school outcomes associated with strong leadership. Edmonds (1979) summarized Weber's (1971) findings by stating "All four schools had strong leadership in that their principal was instrumental in setting the tone of the school; helping decide on instructional strategies; and organizing and distributing the school's resources" (p. 16). Edmonds (1979) concluded one of "the most tangible and indispensable characteristics of effective schools are strong administrative leadership without which the disparate elements of good schooling can neither be brought together or kept together...” (p. 22).

Effective schools research provided an initial empirical finding that school leaders may affect school outcomes. However, the early stages of school leadership research provided neither substantial theoretical support nor a clear definition and delineation of the instructional leadership role. However, these findings, in addition to the long held belief that school leadership matters, led to an increase in the study of school leadership and conceptualization of the construct of instructional leadership.

In reviewing the literature on instructional leadership, this review classifies the literature into three broad categories: early studies, middle studies, and later studies. The early studies review the literature through the early 1980's. The focus of these studies is on early theoretical, 
conceptual, and methodological development. The empirical evidence in this period is sparse. The middle studies period covers from the early 1980's to the mid 1990's, builds on the conceptual development of the early period, and evidences a greater number of empirical studies. The later period reviews the literature from the mid 1990's to the present. It confirms the findings of the middle period and provides further evidence for the suggested model of principal leadership having an indirect relationship on school outcomes such as student achievement. This period also evidences research on the transformational leadership model and concludes by considering a learning-centered leadership model that includes components of the instructional leadership model and the transformational leadership model. Looking at the literature within this framework provides a useful approach to understanding the evolution of the construct of instructional leadership from its origin to its present state

\section{Early Reviews of Instructional Leadership Studies}

While the effective schools research gave impetus to further study and conceptualization of instructional leadership, studies of school administration had been undertaken since the 1960's. Two review studies in the early 1980's, gave the state of the research on instructional leadership from the 1960 's to the early 1980's. After reviewing 322 research reports on school administrators, Bridges (1982) summarized his findings as follows:

The state of the art is scarcely different than what seemed to be in place nearly 15 years ago. Although, researchers apparently show a greater interest in outcomes than was the case in the earlier period, they continue their excessive reliance on survey research designs, questionnaires of dubious reliability and validity and relatively simplistic types of statistical analyses. Moreover, these researchers persist in treating research problems in an ad hoc rather than a programmatic fashion. Equally disturbing is the nature of the 
knowledge base accumulated during this period. Despite the rather loose definition of theory that was used in classifying the sample of research contained in the core collection, most of it proved atheoretical. Likewise, the research seems to have little or no practical utility. In short, there is no compelling evidence to suggest that a major theoretical problem relating to school administrators has been resolved by those toiling in the intellectual vineyards since 1967. (pp. 24-25)

His pessimistic finding of the state of research on school administration had as much to do with methodological concerns as it did with the knowledge base produced by the research. A strong theoretical framework for investigating and understanding the nature of the construct of school administration did not exist. In summary, according to Bridges (1982), although the construct had been studied for a substantial period of time little progress had been made in terms of methodology, theory, or practical findings.

In contrast to these findings, Bossert and his colleagues (1982) were much more optimistic in their review of the research from this period. They were interested in the instructional management role of the principal, especially the role of the principal as an instructional leader. They narrowed the scope of their research more than Bridges (1982). In reviewing the research, Bossert et al. (1982) evidenced positive findings regarding the influence of school leaders on in-school variables and student achievement. The focus of their review was less about the methodological concerns raised by Bridges (1982) and more on the conceptual development of the construct of instructional manager. They considered both the theoretical ties within the literature and the direction of the findings. Bossert and his colleagues (1982) summarized the findings of two studies and posited that these two studies mirrored the findings of the other studies of effective principals and successful schools. They determined four 
behavioral areas of principal leadership: Goals and Production Emphasis, Power and Decision Making, Organization/Coordination, and Human Relations.

However, despite the research coalescing around these domain areas, they noted shortcomings in the usefulness of the research. First, organizational variables needed further analysis so a school leader could effectively enact the behaviors. Little mention was made in the literature of how organizational or contextual variables interacted with the behaviors. Second, the behaviors were based upon the classic model of a bureaucratic, hierarchal, tightly coupled organization in which leadership behaviors monitor subordinate behavior to meet clear performance outcomes. Yet, a typical school organization may not be hierarchal nor may instructional behaviors be directly tied to an outcome such as student achievement. In short, the behaviors are based on an organizational model that may be inconsistent with a school organization.

In light of these shortcomings, Bossert et al. (1982) developed a framework to address these concerns in future research when examining the influence of the instructional manager. They suggested principal management behavior affects both school climate and instructional organization. These in turn affect student learning. This framework attempted to give direction to future research in order to resolve some of the concerns Bossert and his colleagues (1982) had with the current state of the research on instructional management. In particular, they claimed that the research to date failed to produce a body of knowledge that led to practical findings because "aside from the standard educational administration admonitions that describe what a good manager should do, the research and practice literatures do not present models that describe how certain management or leadership acts actually become translated into concrete activities which help children succeed in school" (p.34). Furthermore, the research did not consider the 
complexity of the role of an instructional manager. Previous research had identified behaviors or conditions of successful instructional management but had failed to understand the complexity of the context and variables associated with implementation of the behaviors. Their model was an attempt to represent the variables and complexity associated with instructional management.

One additional review around this same time adds further evidence regarding the state of the conceptual development of the instructional leader construct. Murphy, Hallinger, and Mitman (1983) reported both methodological concerns and conceptualization issues in the research. They stated "the four most important methodological problems in the area of educational leadership: the limited generalizability of findings, the lack of explanatory models, the lack of behavioral indicators for leadership, and the premature application of research findings" (p. 297). Following their explanation of these methodological concerns, they raised concerns related to the definition and conceptualization of instructional leadership. Their concerns are similar to those raised by Bossert et al. (1982) in that they concluded a mismatch existed between the findings in the literature regarding educational leadership and the organizational and institutional models of schools. They concluded their findings with the following caveat: "The methodological considerations discussed are more amenable to improvement than the organizational problems that were examined. However, unless conceptualizations of leadership are constructed within the organizational context of schools, understanding of school leadership will never be as robust as it could be" (p. 302).

The early reviews of the literature on the construct of instructional leadership are characterized by both methodological and conceptualization concerns. These concerns are really two ends of the same stick. Methodological concerns evidence conceptualization concerns. Conceptualization concerns are related to methodological concerns. As methodological concerns 
are resolved the conceptualization of the construct becomes more defined. As efforts are made to better conceptualize and define the construct, methodological improvements are made. The early reviews demonstrate the need for future research to consider the organizational and social context in which instructional leadership is enacted and to include less visible, more indirect behaviors in the conceptualization of instructional leadership.

\section{Middle Reviews of Instructional Leadership Studies}

The middle review summaries demonstrate the methodological advancements and the further conceptual development of the instructional leader construct. Five years after Murphy and his colleagues (1983) reviewed the literature on instructional leadership, Murphy (1988) reported on the methodological progress that had been made in overcoming "first generation research difficulties" identified in his earlier review. After discussing progress and additional methodological challenges, Murphy (1988) focused on conceptual problems. He identified two major areas of concern: failure to specify the contextual aspects of leadership and misunderstandings of leadership. His critique of the first concern is that researchers had established a uniform set of behavioral categories that were to be enacted independently of organizational or social context. Organizational contexts and variables must be considered to fully understand the construct of instructional leadership. His second concern involved a misunderstanding of instructional leadership. Researchers defined instructional leadership behaviors as those behaviors directly connected to teaching and learning. Behaviors not considered to directly affect teaching and learning were classified as management or administrative behaviors. This conceptual misunderstanding separates behaviors or ignores less direct behaviors that could be considered as instructional leadership. Murphy (1988) argued that indirect behaviors (management and administration) of complex organizations (schools) "are 
difficult and challenging functions that can be just as effective in promoting the attainment of school goals as can direct instructional leadership" (p. 128). Consequently, Murphy (1988) called for further research to better define the construct of instructional leadership by examining principals' effects on both mediating and outcome variables and through research "that investigates the more indirect, less visible, and less technical ways that principals exercise their instructional leadership" (p. 131).

Other middle studies reviewers came to a similar conclusion. Hallinger and Heck (1996) reviewed the empirical research on the relationship between the principal's role and school effectiveness between 1980 and 1995. Specifically, they focused on several theoretical models and the conceptual components of those models as well different methods of investigation. They began their review with a cautious tone confessing that the relationship between principal behavior and its effect on school outcomes is complex and not easily given to empirical verification. They gave their perspective that "the principal's role is best conceived as part of a web of environmental, personal, and in-school relationships that combine to influence organizational outcomes" (p. 6). Additionally, they concluded, as have other reviewers of this literature, "the tradition of principal-effectiveness studies has not done justice to this complexity in terms of either theoretical or methodological sophistication" (p. 6). In their review, Hallinger and Heck (1996) identified 40 studies examining the relationship between principal leadership behavior and school effectiveness. The criteria they used to select these studies included: 1) principal leadership as one of the independent variables 2) an explicit measure of school performance as a dependent variable 3) studies outside of the United States were also included. Hallinger and Heck (1996) classified the 40 studies they reviewed according to the three models and a conceptual framework they adapted from Pitner (1988): Model A-Direct-Effects, 
Model B-Mediated-effects, and Model C-Reciprocal-effects. Figure 1 below illustrates the Hallinger and Heck (1006) classification of the different models.

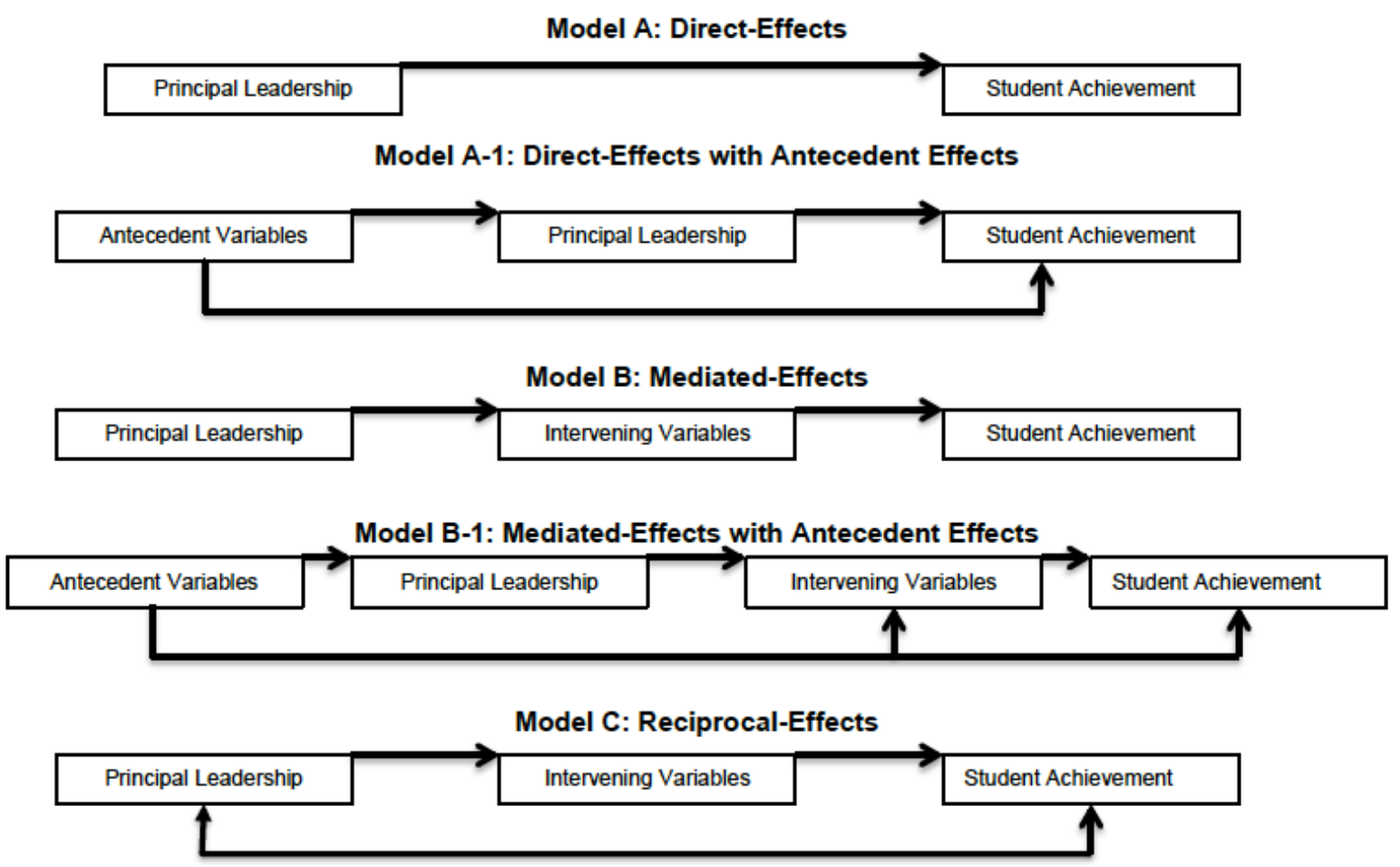

Figure 1. Principal Effects on School Effectiveness. This figure illustrates Hallinger and Heck's (1996) model to consider the effects of leadership and achievement.

The direct-effects model (Model A) assumes that the principal directly affects the outcome of student learning without the presence of intervening variables or features of the school organization. Earlier reviewers criticized this conceptualization of instructional leadership because it failed to consider the context or organization factors that influenced or where influenced by principal behavior. Hallinger and Heck (1996) found no or minimal effect of principal behavior on student achievement from these types of studies. Even when researchers in their study included control variables or included antecedent variables as in Model A1 the findings were ambiguous and not significant. The reviewers criticized the direct-effects 
conceptualization and theoretical model of instructional leadership because it failed to consider the possibility that the relationship between principal behavior and school outcomes is indirect. Principals may affect school outcomes but their behavior is always tied to the actions of others in the school. The direct-effect models ignore the possibility of intervening variables.

The next classification of studies reviewed was the mediated-effects model with and without antecedent variables (Models B \& B1). This model theorized that the effects of principal leadership would occur indirectly by influencing those variables that directly affect student achievement such as the school climate and instructional organization. This model was similar to that suggest by Bossert and his colleagues (1982) mentioned previously and other earlier reviewers (Murphy, 1988).

Within this classification were studies that considered principal behavior as an independent variable and those that considered it as dependent variable affected by antecedent or other control variables. Studies within this model demonstrated an evolving theoretical framework and conceptualization of instructional leadership. Over one third of the studies reviewed by Hallinger and Heck (1996) were of this type. These studies evidenced the complexity of the construct and the influence of both external and internal organizational factors. In addition, their framework acknowledged that leadership behavior influenced school outcomes, but that it is mediated significantly but other people and processes. They acknowledged the relationship was indirect and sought to further understand the nature of and variables associated with the indirect relationship.

They had begun to open the black box. Hallinger and Heck (1996) commended the theoretical richness of Model B studies and noted "Armed with more fully explicated theoretical models and more appropriate statistical techniques, the results demonstrate a different order of 
research when compared to the principal-effects studies reviewed 15 years ago" (p. 28). They also stated that the most valid and significant positive findings came from Models B and B1 even though these studies "used increasingly sophisticated theoretical models, stronger research designs, and more powerful statistical models" (p. 38).

In summarizing their findings of the research classified as Model $\mathrm{C}$, the reciprocal-effects model, Hallinger and Heck (1996) noted that none of the research they considered could be classified according to this model. However, they discussed why this model might provide benefits for future research. The theoretical assumption underlying this model is that not only does leadership affect mediating processes, variables, and school outcomes, but these, in turn, also affect principal leadership. As principals affect other variables and outcomes, they are affected by these outcomes. A reciprocal effect takes places. Hallinger and Heck (1996) suggested three factors have contributed to the lack of research using this model: data requirements, analytical methods, and conceptual bias. Indeed, two stages or evolutions seem evident in the methodological and conceptual development of instructional leadership. Stage one was the direct-effect model; stage two is the indirect-effect model. Hallinger and Heck (1996) suggested that the reciprocal-effect model might be the next stage. Indeed, as the theory of instructional leadership has evolved, so have the conceptual framing and the methodology to analyze and measure it.

Hallinger and Heck (1996) referenced this in their concluding comments about the then current state of the research and recommendations for future research. First, they concluded direct-effects models are not meaningful models to study the construct of instructional leadership because they are not powerful enough to make sense of the complexity of the construct. They do not account for intervening variables or environmental influences. Second, they argued models 
that offer the most promise for future research contextualize the principal in the school and its environment. Principal behavior must be studied in its context and as both a dependent and independent variable. Third, they suggested that due to the complexity of the construct, the nature of the non-experimental research that dominates studies in his field, and limited resources, future studies should consider the relationship between principal leadership and intervening school-level variables and forego the focus on student achievement. The relationships between principal behavior and those mediating variables believed to influence student achievement need to be uncovered.

A majority of the studies reviewed for this section used an instrument known as the Principal Instructional Management Rating Scale (PIMRS) to measure the instructional management or leadership if the principal. The scale developed by Hallinger and Murphy (1985) is based on a conceptual framework that proposed three dimensions in the role of an instructional manager: defining the school's mission, managing the instructional program, and promoting a positive school-learning climate. These three domains are represented by 10 instructional leadership functions. Figure 2 shows the PIMRS conceptual framework. This framework and conceptualization shows the evolution in the construct of instructional management from the earlier reviews. 

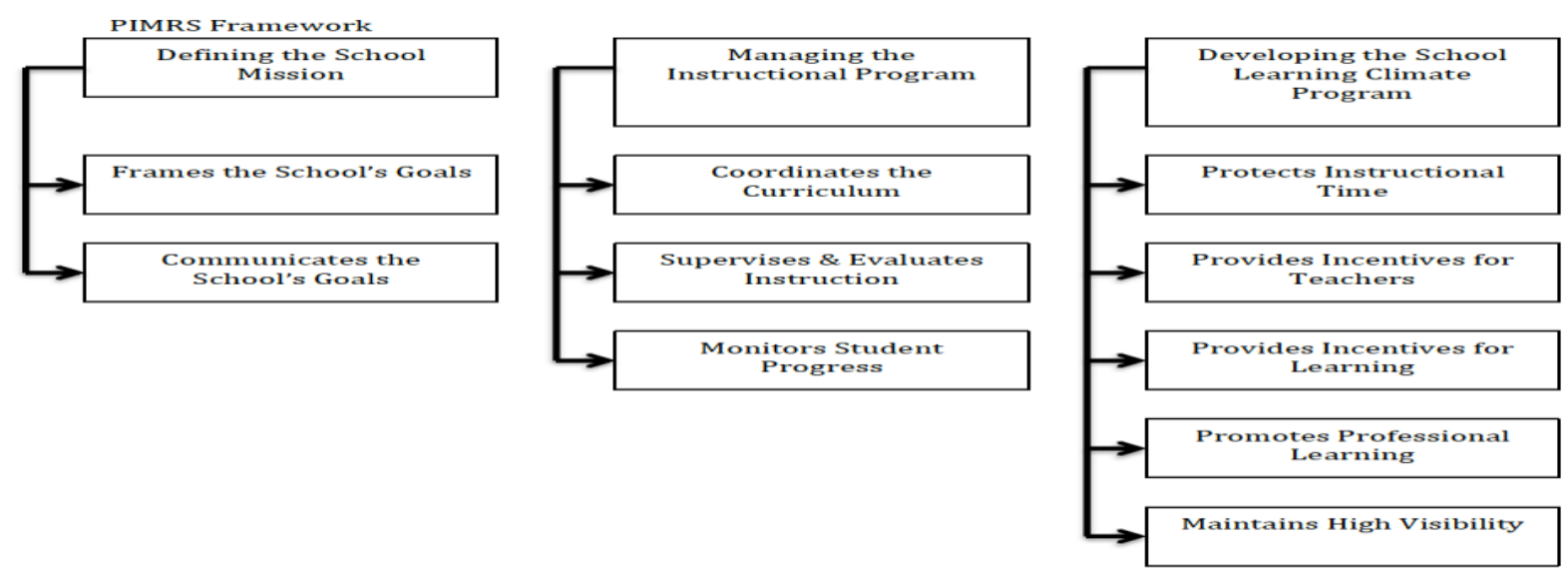

Figure 2. The Principal Instructional Management Rating Scale. This was the scale developed by Hallinger and Murphy (1985) to measure instructional management.

Whereas the early studies evidenced a lack of a theoretical framework and a strong methodology for empirical study of instructional leadership, the middle studies suggested the indirect or reciprocal effects model as the most promising models for future research based on the reviews of the literature. These reviews also posited the methodology had improved sufficiently to support valid findings with such models. The most promising findings from this period were those that came from an indirect-effect model with the most robust and rigorous methodology. The middle reviews concluded that principal behavior did positively affect student-learning outcomes, but it did so indirectly. The conceptualization of instructional leadership was now defined and understood to include more than just the direct instructional behavior of the principal as evidence in the PIMRS framework above. These reviews encouraged future research that focused on uncovering the nature and complexity of the reciprocal relationships between principal behavior and the mediating variables it links with to affect student achievement. The early reviews suggested a possible "black box" of intervening variables (Bridges, 1982). The middle reviews clearly acknowledged the presence of a "black box" and asked the next generation to open up that box to determine the variables in that box and how they are related to each other (Murphy, 1988; Hallinger \& Heck, 1996). 


\section{Later Reviews of Instructional Leadership Studies}

The review of the literature in this later stage considers instructional leadership or the leadership enacted by a principal to affect student outcomes as more than just a finite set of leadership practices. It covers the time period from the mid-1990's to the present. The emphasis of this review period focuses on the indirect nature of the effect. The construct of instructional leadership has evolved to not only include leadership practices specifically targeted at improving student achievement but to also consider how leadership affects context, cultural, and climate variables which may indirectly affect student achievement. Additionally during this later review period, a transformational leadership model was developed as an alternative to the instructional leadership model which some researchers believed focused too much attention on the principal as the source of expertise, power, and authority (Hallinger, 2003). The transformational model and the research associated with it served to expand and further define the construct of instructional leadership. Consequently, the reviews of empirical research in this latest stage call for research methods that account for the more complex nature of instructional leadership and those that seek to understand how instructional leadership affects others and other variables that then affect student outcomes. This period concludes with researchers suggesting that elements of the traditional instructional leadership model and the transformational leadership model be combined into a leadership for learning or a learning-centered leadership model.

The past several years have witnessed as many as six reviews of the empirical research done to better understand the relationship between school leadership and student outcomes (Bell, Bolam, \& Cubillo, 2003; Leithwood, Harris, \& Hopkins, 2008; Leithwood, Louis, Anderson, \& Wahlstrom, 2004; Marzano, Waters \& McNulty, 2005; Robinson, Lloyd, \& Rowe, 2008; Witziers, Bosker, \& Krüger, 2003). These constitute the most recent reviews of the literature on 
instructional leadership. They consider both the traditional instructional leadership approach and the transformation leadership model that emerged during this period. Finally, the most recent research from this later period suggests a synthesis of the traditional instructional leadership model and the transformational model (Hallinger, 2011; Robinson et al., 2008). Most current conceptualizations of instructional leadership include transformational leadership model components. Some researchers suggest the term "learning-centered leadership" for the construct of instructional leadership that has emerged most recently (DuFour, 2002; Goldring et al., 2009; Hallinger, 2011; Murphy et al., 2006; Robinson, 2010).

Bell and colleagues (2003) analyzed eight different studies from various countries that considered the relationship between school leadership and student outcomes. As with the earlier review studies, they found an indirect relationship that "is mediated through key intermediate factors, these being the work of teachers, the organization of the school, and relationship with parents and the wider community" (p. 3). Although, the authors of this study indicated the relationship was indirect they raise concerns that there "is very little research evidence available to illuminate the precise nature of the relationship between the leadership and management strategies adopted by head teachers and the learning outcomes of their pupils" (p. 26).

Cotton (2003) performed a narrative review of the literature on the effect of school leadership on student achievement for her book, Principals and Student Achievement: What the Research Says. She reviewed 81 reports from 1985 to the time of her writing. She identified 25 categories of principal leadership behaviors that were positively associated with student outcomes. Because this was a narrative review, she did not quantify the effect of these categories on student achievement outcomes. She did conclude as did the other researchers in her review 
that the effect of these leadership categories is indirect "mediated through teachers and others" (p. 58).

Marzano et al. (2005) performed a meta-analysis of 69 research studies involving schools within the United States from 1970 to 2001 They specifically considered studies that directly or indirectly examined the relationship between the leadership of the building principal and student academic achievement as measured by standardized or state achievement tests. Based on their research, they identified 21 leadership responsibilities and calculated the average correlation between each responsibility the measure of student achievement associated with the study. The average correlation was .25. They concluded their findings chapter by stating "our meta-analysis indicates that principals can have a profound effect on the achievement of students in their schools" (p. 38).

Witziers et al. (2003) also conducted a quantitative meta-analysis to examine to what extent principals directly affect student outcomes. The studies selected for their analysis were conducted between 1986 and 1996 and were all based on direct effect models because they believed there was a lack of studies employing an indirect effect model. Their analysis led them to conclude "there is no evidence for a direct effect of educational leadership on student achievement in secondary schools" (p. 415). In addition to this conclusion, the authors further proposed "Better conceptualization of the phenomenon of educational leadership is needed. Context and intermediate factors should be taken into account in future research... Different school cultures can indeed be distinguished with different consequences for student outcomes. What is needed is more insight to the role of school leaders in developing and sustaining these cultures" (p. 416). 
The differences in the findings suggested by the two meta-analyses listed above could be attributable to the fact that the Marzano et al. (2005) analysis considered studies of both the direct and indirect effect models. The indirect effect models typically show a higher correlation. Also, the Witziers et al. (2003) analysis focused on studies outside of the United States where effect sizes are typically smaller than those in the United States. Additionally, the researchers used different methods in estimating effect sizes (Marzano et al., 2005). Finally, a majority of the studies used in the Marzano et al. (2005) analysis were unpublished theses and dissertations not subject to the same peer review process as published studies (Robinson et al., 2008).

As mentioned, a transformational leadership model emerged during this later review period. This was in response to a sense that the instructional leadership model focused too much on the role of the principal as the sole source of expertise, power, and influence (Hallinger, 2003). It further acknowledged that the principal played more roles than just the instructional leadership role in leading a school and that the other leadership roles of a principal also affected student achievement. The transformational leadership approach sought to develop the organization's capacity to improve and innovate through a "bottom-up" approach rather than a "top-down" approach focusing on direct coordination or control of curriculum, instruction, and improvement (Hallinger, 2003). The transformation leadership model recognized the indirect effect of principal behavior on student achievement. Rather than further developing and refining the instructional leadership model to account for its indirect effect on student achievement, the transformational leadership model was meant to replace the instructional leadership model. Whereas the instructional leadership model sought first-order effects on learning - to influence those variables that directly affect curriculum and instruction, the transformational leadership model targeted second-order effects on learning - to influence those variables (teachers) that can 
have first-order effects on learning. In the transformational leadership model, the behavior of the principal is to influence those who will influence those variables that improve student achievement—curriculum and instruction.

Hallinger (2003) compared the conceptualization and the findings of the research on both the instructional leadership and the transformational leadership models. Additionally, he discussed the limitations of the findings from both models as practical models for principal behavior. Hallinger (2003) noted that instructional leadership arose as the leadership model of choice from the effective schools research of the 1980's. During the 1990's restructuring movement with a more bottom-up less top-down leadership approach, transformational leadership became the leadership model of choice. However, at the turn of the century reform and accountability efforts sought to "bring more powerful methods of learning and teaching to bear on the practices of schools" (p. 342). Consequently, the focus has returned to the instructional leadership model. Noting the two models are more similar than different, Hallinger (2003) proposed an integrated model that would better conceptualize and account for the variables that affect and are affected by principal leadership. According to Hallinger (2003), this model of leadership in education would not have the principal do it alone. He agreed with Lambert (2002) who stated, "The days of the lone instructional leader are over. We no longer believe that one administrator can serve as the instructional leader for the entire school without the substantial participation of other educators" (p. 37). Hallinger (2003) further suggested that this leadership model "must be conceptualized as a mutual influence process, rather than as a one-way process in which leaders influence others. Effective leaders respond to the changing needs of their context" (p. 346). Additional reviews and research in this later period confirm the finding and suggestions of Hallinger (2003). 
Robinson and her colleagues (2008) did an analysis of the findings of 27 published studies on the relationship of leadership and student outcomes. They were interested in determining the effect of different types of leadership on student outcomes. Their study consisted of two meta-analyses. The first compared the effects of transformational and instructional leadership on student outcomes. This analysis consisted of 22 of the 27 studies. The second analysis compared the effects of five sets of inductively derived leadership practices on student outcomes. Their findings indicate that the effect size of instructional leadership is three to four times greater than that of transformational leadership. Although the effect of instructional leadership is significantly higher than transformational leadership, the authors caution "in general, abstract leadership theories provide poor guides to the specific leadership practices that have greater impacts on student outcomes" (p. 658). They then discussed the findings of their second analysis regarding the five sets of leadership practices. Those practices are: establishing goals and outcomes; resourcing strategically; planning, coordinating, and evaluating teaching and the curriculum; promoting and participating in teacher learning and development; ensuring an orderly and supportive environment. The table below indicates the practices, average effect sizes in terms of standard deviations, and the strength of that effect.

Table 1

\section{Sets of Leadership Practices}

\begin{tabular}{lcc} 
Practice / Dimension & Average Effect Size & Strength of Effect \\
\hline Establishing goals and expectations & 0.42 & Moderate \\
Resourcing strategically & 0.31 & Small \\
$\begin{array}{l}\text { Planning, coordinating, and evaluating teaching } \\
\text { and the curriculum }\end{array}$ & 0.42 & Moderate \\
$\begin{array}{l}\text { Promoting and participating in teacher learning } \\
\text { and development }\end{array}$ & .84 & Large \\
Ensuring an orderly and supportive environment & 0.27 & Small \\
\hline
\end{tabular}


Following their summary of these leadership practices and their effect, the authors shared general findings. First, Robinson and her colleagues (2008) stated that "the closer educational leaders get to the core business of teaching and learning, the more likely they are to have a positive impact on students' outcomes" (p. 664). Second, the motivational, collaborative, and interpersonal skills associated with transformational leadership are embedded in the construct and practices of instructional leadership. As demonstrated by the five practices indicated above, the construct of instructional leadership is an integration of both task and interpersonal behaviors. This finding is supported by additional research that considered the impact of transformational leadership compared to instructional leadership (Leithwood \& Jantzi, 2005; Marks \& Printy, 2003).

In this later review period, the traditional construct of instructional leadership is conceptualized to include indirect behaviors in addition to those behaviors that directly affect instruction. Effective instructional leadership is assumed to include not only those behaviors that directly affect instruction but also those transformational behaviors that indirectly affect student learning. Thus the instructional leadership construct is conceptualized to include other indirect behaviors that indirectly affect student achievement by affecting the conditions, people, and factors in schools that encourage student learning. This new conceptualization of instructional leadership takes into consideration the knowledge the research has surfaced over the past several decades about effective principal leadership that influences student learning.

Several researchers conceptualize this construct as leadership for learning, learningfocused leadership, or learning-centered leadership (DuFour, 2002; Goldring et al. 2009; Hallinger, 2011; Hallinger \& Heck, 2010; Knapp, Copland \& Talbert, 2003; Knapp, Copland, Honig, Plecki, \& Portin, 2010; Marks \& Printy, 2003; Murphy et al., 2006; Robinson, 2010). 
DuFour (2002) suggested "redefining the role of the principal from instructional leader with a focus on teaching to a leader of a professional community with a focus on learning" ( $p$. 15). He further stated that an instructional leadership emphasis focused on inputs and intentions whereas learning-centered leadership emphasis focuses on outcomes and results.

Marks and Printy (2003) suggested an integration of instructional leadership and transformational leadership into a construct they referred to as integrated leadership. They explained that two traditional leadership models have existed in the literature on principal leadership —instructional leadership and transformational leadership. Instructional leadership emerged from the effective schools research in the 1980's. It was the principal's role to oversee and lead instructional improvement. It was considered a hierarchical, top-down approach. With the late 1980's restructuring movement's emphasis on a more democratic, bottom-up approach teachers were given more voice and a greater role. This decentralization led to a different leadership model than the traditional instructional leadership model. Scholars emphasized the transformational leadership model that focused creating a shared vision of improvement and in motivating others to achieve that vision of improvement. The principal's role also included affecting organizational culture. The Marks and Printy (2003) research focused on considering the effect of combining these models into an integrated leadership model on student performance. They found that "where integrated leadership (transformational leadership coupled with shared instructional leadership) was normative, teachers provided evidence of high-quality pedagogy and students performed at high levels on authentic measures of achievement" (p. 392). The researchers conceptualized instructional leadership as integrated leadership that is a combination of instructional leadership and transformational leadership. 
Hallinger and Heck (2010) explained this new conceptualization of leadership for learning accordingly: "In our view, this approach to leadership represents a blend of two earlier leadership conceptualizations: instructional leadership and transformational leadership" (p. 267). From instructional leadership, leadership for learning emphasizes, "creating and sustaining a school-wide focus on learning" and from transformational leadership an emphasis on capacitybuilding or the learning of the teachers and staff (p. 657).

Hallinger (2011) later stated

The fervor of debates over which model offers the greatest leverage for understanding how school leaders contribute to learning has reduced in recent years. Empirical results over a large number of studies have begun to show a fairly consistent pattern of impact, and today, the term 'leadership for learning' has come to subsume features of instructional leadership, transformational leadership, and shared leadership. (p. 126) Knapp et al. (2003) stated that "leading for learning means creating powerful, equitable learning opportunities for students, professionals, and the system and motivating or compelling participants to take advantage of these opportunities" (p.12). They suggested five areas of action for school and district leaders engaged in leading for learning: establishing a focus on learning, building professional communities that value learning, engaging external environments that matter for learning, acting strategically and sharing leadership, and creating coherence.

Murphy and his colleagues (2006) in developing a conceptual foundation for learningcentered leadership suggested that two strands of leadership have emerged as especially prevalent in high performing schools over the past three decades. The first they labeled as "leadership for learning" or instructionally focused leadership. Behaviors in support of this leadership approach include staying "consistently focused on learning — the core technology of 
schooling: learning, teaching, curriculum, and assessment; and make all the other dimensions of schooling work in the service of a more robust core technology and improved student learning" (p.3). The second strand was change-oriented leadership or transformational leadership. The focus in this strand was on organizational processes- -employing effective methods for getting the school and its members to become more productive" (p. 3). The authors suggested that these two strands are most effective when combined. They conceptualized this combination as learning-centered leadership. The authors continued by suggesting a leadership model for learning-centered leadership. Within the model is a set of leadership behaviors that are influenced by four major conditions. These behaviors in turn indirectly affect student success outcomes. The behaviors are mediated by school operations and classroom activities. The authors suggested eight dimensions of learning-centered leadership: vision for learning, instructional program, curricular program, assessment program, communities of learning, resource acquisition and use, organizational culture, and social advocacy. They provided a literature base and justification for each dimension of learning-centered leadership. The authors developed this framework to inform the creation of a new evaluation system for school leaders.

Golding et al. (2009) in their article Assessing Learning-Centered Leadership:

Connection to Research, Professional Standards, and Current Practices provided the rationale for their conceptual framework which is the blueprint for their instrument to assess leadership performance - the Vanderbilt Assessment of Leadership in Education (VAL-ED). Their "conception is aligned with a research-based definition of educational leadership that is rooted in school improvement...learning-centered leadership" (p. 4). Their conceptual framework was based on two dimensions of leadership behaviors - core components and key processes. Core components consist of leadership behaviors that have been traditionally associated with 
instructional leadership. The core components are: high standards for student learning, rigorous curriculum, quality instruction, culture of learning and professional behavior, connections to external communities, and systemic performance accountability. They are those behaviors that "support the learning of students and enhance the ability of teachers to teach" (p.5).

Key processes are "leadership behaviors, most notably aspects of transformational leadership traditionally associated with processes of leadership that raise organizational members' levels of commitment and shape organizational culture" (p. 5). These key processes are: planning, implementing, supporting, advocating, communicating, monitoring. As with other researchers, they posited that learning-centered leadership behaviors would have an indirect effect on student success. Leadership behaviors affect school performance that can in turn affect student success. They conceptualized instructional leadership to include the components of transformational leadership and refer to this combined conceptualization as learning-centered leadership. The combining of these two types of leadership behaviors by Goldring et al. (2009) is similar to the conclusion reached by other researchers in this later review period (Hallinger, 2011; Hallinger \& Heck, 2010; Knapp et al., 2003). These core components and key process are aligned with the Interstate School Leaders Consortium (ISLLC) standards.

As part of the research project, Learning from Leadership, funded by the Wallace Foundation to explore the relationship between school leadership and student achievement, Leithwood et al. (2004) sought to build the knowledge base regarding effective educational leadership with regards to the following five key questions about leadership practices and influences on student learning: what effects does successful leadership have on student learning, how should the competing forms of leadership visible in the leadership be reconciled, is there a common set of basic leadership practices used by successful leaders in most circumstances, what 
else is required for successful leadership, how does leadership exercise its influence on the learning of students? They determined three general findings from their research about the influence of school leadership on student achievement. First, the influence is indirect through other people and features of the organization. Second, the research gives some good clues about who those individuals and what those organizational features are. Third, more research needs to be done to determine how school leadership influences others and other features of the organization. They expressed the concern that "Principals...are all being admonished to be instructional leaders without much clarity about what the term means" (p. 4). The term has become more a slogan than a set of specific leadership practices. After reviewing the then current state of the research on educational leadership and student achievement, they offered suggestions for future research:

Research about the forms and effects of leadership is becoming increasingly sensitive to the contexts in which leaders work and how, in order to be successful, leaders need to respond flexibly to their contexts. Such evidence argues for research aimed less at the development of particular leadership models and more at discovering how such flexibility is exercised by those in various leadership roles. Research is also urgently needed which unpacks, more specifically, how successful leaders create the conditions in their schools which promote student learning. School-level factors other than leadership that explain variation in student achievement include school mission and goals, culture, participation in decision making and relationships with parents and the wider community. These are variables over which school leaders have considerable potential influence and we need to know more about how successful leaders exercise this influence. (pp. 22-23) 
Robinson (2010) argued that while there is considerable evidence about effective leadership practices much less is known about how leaders engage in these behaviors. She quoted Smylie and colleagues (2005) who stated

We contend that knowledge of effective leadership practices is not the same thing as knowledge of the capacities required for enactment. Our understanding of effective school leadership has grown tremendously in recent years...However, our understanding of the knowledge, skills, and disposition required for school leaders to be effective is much less well developed. (p. 141).

Robinson (2010) uses the term capabilities to describe the knowledge, skills, and dispositions necessary for effective instructional leadership. She goes on to provide empirical evidence as support for the three capabilities: using leadership content knowledge, solving complex problems, and building relational trust. After providing the empirical evidence and justification for each capability, Robinson (2010) summarized her findings accordingly

To put it in the simplest terms, effective instructional leadership probably requires leaders to be knowledgeable about how to align administrative procedures and processes to important learning outcomes, to be highly skilled in using their knowledge to solve the myriad of problems that arise in the course of improving learning and teaching in their own contexts, and to use their knowledge, their problem solving ability, and their interpersonal skills in ways that build relational trust in their school community. (p. 21) She concluded by suggesting further research to surface greater understanding of the meaning and possible dimensions of the capabilities. She warned, however, that further specifying capabilities might lead to a list of behavior expectations. This is problematic because "Learning to lead is not about mastering a long list of capabilities. It is about learning how to draw on and 
integrate appropriate cognitive and emotional resources in context-sensitive and goal-relevant ways" (p. 23).

In summarizing this latest section of research on instructional leadership, one can draw at least three conclusions. First, researchers are now conceptualizing the construct of instructional leadership to include behaviors beyond traditional instructional leadership behaviors focused directly on aspects of teaching and learning. Transformational leadership behaviors, once considered a separate conceptualization of effective principal leadership, are now considered part of the current conceptualization of instructional leadership. This conceptualization is increasingly being referred to as leadership for learning or learning-centered leadership. Second, learning-centered leadership clearly has an indirect effect on student achievement. Learningcentered behaviors affect organizational, personnel, and other factors that affect student achievement. Third, research on learning-centered leadership needs to expand beyond defining a specific set of behaviors to consider how leaders create conditions in schools that promote increased student achievement. In other words, how does leadership affect school level factors that in turn affect student performance?

\section{Trust}

This study assumes that faculty trust in the principal is one the school level factors that is affected by the learning-centered behavior of a principal. Greater levels of faculty trust in the principal create organizational conditions that indirectly affect student achievement. Bryk and Schneider (2002) indicated, "Relational trust does not directly affect student learning. Rather, trust fosters a set of organizational conditions, some structural and others social-psychological, that make it more conducive for individuals to initiate and sustain the type of activities necessary to affect productivity improvements" (p. 116). This next section of the literature review will 
focus on the literature base supporting the construct of faculty trust in the principal. It will be organized by first considering how trust has been classified and defined for this study based on the literature. This will include a discussion of the dimensions or facets of trust. Next the review will consider trust in organizations and trust in schools. The review will conclude with a focus on the literature supporting faculty trust in the principal

Classification of trust. Trust has been defined and classified in multiple ways depending on the discipline employing the definition. Bryk and Schneider (2002) suggest the term "relational trust" to describe the trust that exists among the interpersonal relationships and social interactions within a school. Participants associated with a school (parents, students, teachers, and administrators) are mutually dependent (interdependent) on each other to achieve the goals of the organization. Each participant relies on others to fulfill their responsibilities. They expect others to be acting with good intentions. This interdependency causes a feeling of vulnerability. Interdependence is necessary condition of trust (Rousseau et al., 1998). Bryk and Schneider (2002) distinguish relational trust from the trust participants unconditionally place in an institution (organic trust) and the type of trust that is directed by established rules and expectations (contractual trust). It is the consideration of the intentions of another party that distinguishes relational trust from other types of trust. In relational trust, interdependent parties trust one another when they discern the intentions, beliefs, and actions of another within a set of role relations (teacher to student, principal to teacher, parent to teacher etc.) Additionally, they suggest four criteria are necessary for relational trust to be established: respect, competence, personal regard for others, and integrity.

Most of the subsequent research on relational trust in educational settings has used the Bryk and Schneider (2002) classification of relational or interpersonal trust. Additionally, the 
Hoy and Tschannen-Moran (1999) definition has also been widely used in the study of trust levels in schools. This study considers the trust relationship between a faculty and the principal as relational trust.

Definition and dimensions of trust. Trust scholars across disciplines have defined trust similarly and noted the multi-dimensional nature of trust (Bryk \& Schneider, 2002; Burke et al, 2007; Dirks \& Ferrin, 2002; Hoy \& Tschannen-Moran, 1999; Mayer et al, 1995; Mishra, 1996; Rousseau et al., 1998). One of the most common dimensions of trust in the literature is vulnerability. Vulnerability stems from interdependence-a necessary condition of trust. Interdependence exists when one party's interests cannot be achieved with relying on another. If there is no interdependence, there is no need for trust. Rousseau and colleagues (1998) in reviewing the literature on trust across multiple disciplines suggested, "confident expectations and a willingness to be vulnerable are critical components of all definitions of trust" (p. 394). They surfaced two additional fundamental conditions or dimensions of trust suggested in their cross-discipline review of trust—risk taking and interdependence. Risk is the perceived probability of loss. Interdependence occurs "where the interests of one party cannot be achieved without reliance on another" (p. 395). They defined trust as follows: "Trust is a psychological state comprising the intention to accept vulnerability based upon positive expectations of the intentions or behavior of another" (p. 395).

Mishra (1996) in her review of trust literature defined trust as “one party's willingness to be vulnerable to another party based on the belief that the latter party is (a) competent, (b) open, (c) concerned, and (d) reliable" (p. 266). She refers to four dimensions of trust in her definition: competence, openness, concern, and reliability. 
Mayer and colleagues (1995) defined trust as "the willingness of a party to be vulnerable to the actions of another party based on the expectations that the other will perform a particular action important to the trustor, irrespective of the ability to monitor or control that other party" (p. 712). The researchers also defined ability, benevolence, and integrity as factors of trustworthiness.

Burke et al. (2007) in reviewing the extant literature on trust in leadership accepted the Rousseau et al. (1998) definition of trust and determined three categories of trustee characteristics: ability, benevolence, and integrity. These are similar to the Mayer et al. (1995) factors of trustworthiness. Dirks and Ferrin (2002) also examined the findings and implications of four decades of trust in leadership. They noted the commonality of most definitions of trust in referring to the Rousseau et al. (1998) definition noted above. They differentiated two dimensions of trust in the literature. The affective dimension addressed the relationship that one might have with the trustee. This dimension of trust explained the perception that the person trusting the leader perceives that the leader will act for the well being of the trustee. The cognitive dimension is reflected in the belief that the trustee is competent, reliable, and just.

Bryk and Schneider (2002) developed a conceptualization of relational trust as a threelevel theory. First, relational trust is based on the cognitive activity of discerning the intentions of others. Second, the discernments are undertaken and influenced by the institutional norms of schooling as well as the individual context and culture in which they occur. Finally, relational trust results in important consequences for the organization as a whole and for individuals within the organization. In addition to this theoretical definition, they suggested four criteria for discernment or dimensions of relational trust: respect, competence, personal regard for others, and integrity. Respect "involves recognition of the important role each person play's in a child's 
education and the mutual dependencies that exist among various parties involved in this activity" (p. 23). Competence is fulfilling one's role and responsibilities well in service of achieving desirable outcomes. Personal regard for others is necessary due to the mutual dependence and vulnerability associated with the social exchanges that occur with a school setting. This discernment is understood in terms of actions that show concern for the well being and development of others. Integrity is discerned as others sense consistency between what members of the organization say and do.

Hoy and Tschannen-Moran (1999) reviewed four decades of the existing literature on trust and found 16 different definitions. In synthesizing their findings, they proposed the following definition: “Trust is an individual's or group's willingness to be vulnerable to another party based on the confidence that the latter party is benevolent, reliable, competent, honest, and open" (p. 189). This synthesis of trust definitions reported led them to establish five faces or facets of trust: benevolence, reliability, competence, openness, and honesty. Benevolence is the consideration for the needs of another and a willingness to promote their interests. Reliability is the consistency and predictability of positive behaviors. Competence refers to the skills and abilities needed for the task or responsibilities of the position or role. Honesty is commitment to the truth and promises made to another. Finally, openness is transparency in decision-making and the sharing of relevant information and control. These facets are reflective of the literature regarding the multi-dimensional nature of trust.

As mentioned in the introduction of this section, common components and a similar definition of trust are found among trust scholars. Trust involves a willingness of one party to be vulnerable and take a risk based upon the discernment that the other party has certain characteristics. For the purposes of this study, trust is conceptualized as relational or 
interpersonal trust--the trust that a faculty has in the principal. Additionally, this study utilizes the Hoy \& Tschannen-Moran (1999) definition of trust “Trust is an individual's or group's willingness to be vulnerable to another party based on the confidence that the latter party is benevolent, reliable, competent, honest, and open" (p. 189).

Trust within organizations. Organizations consist of individuals who are interdependent upon each other to affect organizational outcomes. Trust among individuals within an organization has been found to have positive, significant effects on individual as well as organizational outcomes. Kramer (1999) in a review of the literature on trust in organizations summarized the benefits of trust within organizations. He categorized the positive outcomes of trust into three categories: reduced transaction costs, increased spontaneous sociality among organizational members, facilitating appropriate forms of deference to organizational authorities. Consequently, when interpersonal trust levels within an organization are high, members of the organization are more likely to exchange assets with one another to mutually benefit each other and the organizations ability to compete and solve problems. Additionally, greater levels of trust between members of an organization is related to the willingness of members to increase their sociality which is operationalized as a willingness to engage in extra behaviors beyond normal expectations for the organizations collective well-being and attainment of collective goals. Finally, higher trust levels in organizations affects individuals' feelings of obligation toward the organization and their willingness to comply with regulations and directives and to voluntarily defer to authorities within the organization.

Mayer and colleagues (1995) suggested an integrative model of trust in which a willingness to take risk in a relationship was the proximal outcome of trust. They argued a need for trust in an organization because "Working together often involves interdependence, and 
people must therefore depend on others in various ways to accomplish their personal and organizational goals" (p. 710). This dependency involves risk on the part of the trustor. Greater levels of trust lead to a greater willingness to assume risk in a relationship.

Dirks and Ferrin (2001) in reviewing the research on the role of trust and organizational outcomes found significant, positive effects of trust on organizational citizenship behaviors and individual performance. They found further supportive evidence on the relationship of trust and worker attitude, job satisfaction, acceptance of information, and workplace perceptions and attitudes.

Megan Tschannen-Moran (2001) suggested several organizational outcomes for an organization with a climate of trust. First, organizational members with a high degree of trust are more open and share more accurate and relevant information. Second, they are willing to do more than the minimal expectations of their job requirements. Finally, members of high-trust organizations feel more comfortable and focus more on organization goals than on selfprotection.

Trust in schools. Schools are organizations and social institutions that depend on the interpersonal relationships that exist and the exchanges that occur daily within the organization for organizational outcomes. Given the positive relationship within organizations of trust and organizational outcomes, educational researchers have considered the relationship of trust and positive educational outcomes. Megan Tschannen-Moran (2004) referred to trust as a both "a glue and a lubricant" (p. 15). Trust binds participants in a school together as they work together and depend upon each other in their collective and collaborative work to accomplish organizational goals. As in other organizations, trust fosters relationships between participants in 
a school. Trust is a lubricant to an organization that allows for a greater flow and efficiency of communication, information exchange, and resource utilization.

Arguing the need for trust in schools, Louis and Wahlstrom (2011) stated "Neither organizational learning nor professional community can endure without trust" (p. 55). Based on findings from their survey in 2004 of 8,000 principals and teachers, they determined that teachers' trust in their principals "provides the firm foundation for learning and for forming professional communities" (p. 55). Additionally, they found that instructional leadership behaviors on the part of the principal (talking with teachers about instruction, visiting classrooms, making instructional quality a visible priority) increases the likelihood that teachers will trust their principal.

Bryk and Schneider (2002) stated that "trust relations culminate in important consequences at the organizational level, including more effective decision making, enhanced social support for innovation, more efficient social control of adults' work, and an expanded more authority 'to go the extra mile' for the children" (p. 22).

Research has shown both a direct and an indirect relationship between trust in schools and student achievement. Bryk and Schneider (2002), in a review of the data from a study of Chicago elementary schools, found a significant positive relationship between the levels of relational trust in a school and school productivity. In summarizing their findings they stated:

In general the composite trust measure is highly predictive of school productivity trends. Schools reporting strong positive trust levels in 1994 were three times more likely to be categorized eventually as improving in reading and mathematics than those with very weak trust reports. By 1997, schools with strong positive trust reports had a one in two chance of being in the improving group. In contrast, the likelihood of improving for 
schools with weak trust reports was only one in seven. Perhaps most telling of all, schools with weak trust reports in 1994 and 1997 had virtually no chance of improvement in either reading or mathematics. (p. 111)

The researchers reached these conclusions even after controlling for other variables of school context, student composition, and teacher background.

Goddard, Salloum, and Berebitsky (2009) considered the relationship between teachers' trust in parents and students and its relationship to student achievement. The researchers surveyed teachers at 80 elementary schools. They had a response rate of $62 \%$. They found a strong positive relationship between trust and school achievement as measure by 4th grade math achievement scores. They also found a marginally significant relationship between trust and school achievement as measured by 4th grade reading achievement scores. The researchers in controlling for variables such as racial composition, socio-economic disadvantage, school-size, and other aspects of school context concluded, "Trust is a strong independent positive predictor of student achievement. That is, trust seems to make a difference to academic achievement above and beyond the influence of school context" (p. 307).

In addition to direct effects on student achievement, research has also established significant, positive relationships between trust levels in a school and other variables that affect student achievement. Trust affects school climate and other organizational conditions that promote a positive culture for student achievement.

Louis (2007) conducted a qualitative study on how trust affected teachers' willingness to work with innovations introduced by central office administration. Five high schools that were working on a district direct quality management initiative were selected for the study over a three year period of time. Although not designed into the study, trust surfaced as a theme from the 
interviews and group study sessions. The analysis of data sought to answer the question: "how does administrator-teacher trust affect the way teachers talk about and interpret district change initiatives" (p. 17). From the data of the study, two schools were classified as high trust and high willingness to change. Three were classified as low trust and willingness to change. Louis found that schools with higher levels of expressed teacher trust in administration were more likely to successfully implement complex change initiatives. From the interviews and study groups, she also concluded "Relational trust rather than institutional trust appears to be at the core of teachers' experience with change" (p. 17).

Megan Tschannen-Moran (2001) studied the relationship between collaboration, shared decision-making, and trust. She argued that with increased teacher collaboration, instructional strategies and policies would improve because teachers would be willing to share their expertise. In surveying 898 teachers from 45 elementary schools, she found that principal/teacher collaboration had a significant, positive relationship with teacher collaboration with peers. Teacher collaboration also had a significant and positive relationship with faculty trust in the principal. She concluded that schools with higher levels of trust have stronger levels of collaboration between teachers and their principal and teachers and their colleagues.

Teacher efficacy has also been found to be positively related to increased student achievement. Goddard, Hoy, and Hoy (2000) found that teacher trust in colleagues was correlated to teacher efficacy by surveying 460 elementary teachers from 47 schools. Additionally, they determined that teacher efficacy was positively associated with student achievement as measured by math and reading scores on standardized tests.

School mindfulness was another organizational variable studied by school trust researchers. Hoy and colleagues (2006) defined school mindfulness as the ability of a school to 
identify problems and apply innovative solutions in a timely manner. Trust was believed to foster school mindfulness because trust created a school culture in which teachers could challenge established practices and behaviors, take risks, and try new strategies. The researchers administered a school mindfulness and a trust survey to 2600 teachers in 75 middle schools. They found strong positive relationships between school mindfulness and both faculty trust in the principal and faculty trust in their colleagues. They concluded that school mindfulness is dependent on trust creating an environment in which teachers are willing to identify problems and work toward new solutions. Teachers take risks in cultures of trust.

The research literature on trust in schools as reviewed above clearly demonstrates a significant, positive relationship between trust levels in school and positive school outcomes that both directly and indirectly affect student achievement. Trust within a school creates a culture or climate within the school that encourages positive behavior on the part of the members of the school. These behaviors lead to greater achievement and progress by the school in accomplishing its goals and purposes. The next section of the review will narrow the focus from trust levels in schools to faculty trust in the principal.

Faculty trust in the principal. While school trust research has focused on a number of referents of the interpersonal relationships that exist within a school (faculty trust in students and parents, faculty trust in colleagues, parent trust in faculty), faculty trust in the principal is the focus of this study. Bryk and Schneider (2002) discussed the reciprocal vulnerabilities inherent in teacher-principal relationships. The teacher-principal relationship is typically hierarchical because of the lower-status nature of teachers. Additionally, because principals are in a position of authority over teachers, they exercise more power over the relationship than do teachers. Teachers risk being treated unfairly or having work conditions that do not enhance their 
effectiveness. They are dependent upon their principal. Principals risk having their teachers be unproductive or undermine the work and improvement of student learning. Principals and teachers face risks and are interdependent and vulnerable. Relations of trust can lessen these vulnerabilities. Principals can affect the level of trust and thus reduce vulnerability through their interactions with and behavior towards teachers. Bryk and Schneider (2002) suggested that principals affect relational trust when they "acknowledge the vulnerabilities of others, actively listen to their concerns, and eschew arbitrary actions" (p. 137). When they add to these behaviors, a compelling vision of improvement and their actions further that vision their integrity is established. These actions combined with competent management of daily operations leads to conditions that foster faculty trust in the principal. In summary, faculty trust in principal is more likely when principals are competent in their role and responsibilities, create a vision for improvement, have integrity in their actions, and show concern for others in the process. As mentioned in the review of research on trust in schools, faculty trust in the principal has significant positive relationships to school outcomes that directly and indirectly affect student achievement. Additional research on faculty trust in the principal has reached similar conclusions and surfaced specific principal behavior that is positively associated with faculty trust in the principal. Hoy and Sweetland (2001) surveyed teachers in 97 high schools to test the hypothesis that the more enabling the school structure the greater the extent of faculty trust in the principal. Principals that help teachers solve problems, encourage open communication, and assist teachers in doing their job without concern for conflict and punishment create enabling structures in their schools. The results of their survey showed that the hypothesis was supported—enabling school structures are significantly and positively related to faculty trust in the principal. 
Tarter and colleagues (1989) studied the relationship of organizational climate and faculty trust in the principal. They hypothesized that an open organizational climate would be positively correlated with faculty trust in the principal. An open organizational climate was conceptualized as supportive and non-directive principal behavior. A supportive principal attempts to motivate teachers with constructive criticism and by setting an example of hard work. Supportive principals also genuinely care about the professional and personal welfare of their teachers. Directive principal behavior is characterized by rigid and domineering monitoring and control with minimal freedom for teachers to exercise professional judgment. The researchers collected data from 72 high schools in New Jersey. A random set of teachers in each school was asked to respond to the instruments. A total of 1083 teachers responded. They found that while supportive and non-directive principal behaviors are both positively related to higher levels of faculty trust in the principal, supportive behavior has a stronger relationship with faculty trust in the principal. They stated, "Principals who are helpful and genuinely concerned about the personal and professional welfare of their teachers are most likely to have the trust of their teachers" (p. 305). Furthermore, they found that the leadership behavior of the principal determines faculty trust in the principal not the interrelationships among teachers.

Moye et al. (2005) studied the relationship between teacher empowerment and interpersonal trust by surveying 539 teachers in 21 elementary schools. Teacher empowerment was conceptualized as a motivational construct with four cognitive dimensions: meaning, competence, self-determination, and impact. Meaning was defined as the value of work goals or purposes. Competence was the belief a teacher held in his or her capacity to perform activities with skill. Self-determination referred to a sense of having a choice in initiating and regulating actions. Impact was the degree to which a teacher could influence outcomes at work. The 
researchers found that "teachers who find their work important and personally meaningful, who report significant autonomy in their work, and who perceive they have influence over their work environment reported higher levels of interpersonal trust in their principals” (p. 270).

Additionally, they stated, "if schools hope to reap the benefits of a trusting work environment, it is the responsibility of the principals to initiate trusting relationships through trustworthy behavior. They can engage in behaviors that promote trust and demonstrate consistency, integrity, concern, and willingness to share control" (p. 272).

A study by Tschannen-Moran (2003), considered the relationship between trust and organizational citizenship. She defined organizational citizenship as the willingness of teachers to do more than their minimum job description requirements. Her premise was that effective schools have teachers who do more than the basic requirements. She surveyed 3,000 teachers in 55 middle schools about transformational leadership, organizational citizenship behaviors, and faculty trust in the principal. She found a moderate but significant effect of trust in the principal on teacher organizational citizenship behavior. The strongest positive relationship in her study was between the transformational leadership behaviors of a principal and faculty trust in the principal. This finding is supported by the research of Hoy et al. (2002) who determined the collegial leadership of a principal has a strong, positive relationship with faculty trust in the principal. They argued, "Leaders who are open with teachers, treat them as colleagues, are friendly and considerate, and who set reasonable standards are not only accepted by their teachers but are rewarded with their trust" (p. 47).

Another study by Tschannen-Moran (2009) in which she surveyed 2355 teachers in 80 middle schools determined that teacher professionalism was also associated with faculty trust. She hypothesized that the degree of teacher professionalism was related to the professional 
orientation of the principal in the exercise of administrative authority and the trust levels evident among various participants in the school community. Teacher professionalism was defined as the degree to which teachers take work seriously, demonstrate high commitment levels, go beyond minimal expectations to meet student needs, respect and work collaboratively with peers, and enthusiastically engage in teaching processes. A principal who has a professional orientation applies rules flexibly, shares control, and allows work process and procedures to be open to deliberation. The results of her study showed "that teachers demonstrate greater professionalism where leaders demonstrate a professional orientation and where greater trust is evident throughout the organization" (p. 239).

In summary, the research on faculty trust in the principal demonstrates two consistent findings. First, the behavior of the principal has a significant and positive effect directly on faculty trust in the principal and indirectly on other positive school outcomes. Second, the behaviors associated with higher levels of faculty trust in the principal are representative of the facets or components of trust discussed early. Namely, teachers trust principals when they are willing to be vulnerable to the actions of the principal based on the confidence that the principal is benevolent, reliable, competent, honest, and open (Tschannen-Moran, 2004). 


\section{APPENDIX B: METHODS}

\section{Problem Statement}

Principals are increasingly being held accountable for positive school outcomes. Adding to this pressure are findings from research that clearly show principal leadership makes a difference in schools (Leithwood, Seashore Louis, Anderson, \& Wahlstrom, 2004; Marzano, Waters, \& McNulty, 2005; Robinson, Lloyd, \& Rowe, 2008; Witziers, Bosker, \& Krüger, 2003). However, this research consistently claims that principal leadership indirectly affects school outcomes such as student achievement. Principals affect variables that in turn affect positive school outcomes. Principals face a problem when they are held accountable for an outcome for which they are dependent upon others and other variables. Principals will benefit from knowing how their leadership affects other variables that are positively associated with school outcomes. Faculty trust in the principal is one variable affected by the leadership of the principal that has been shown to have a positive effect on school outcomes such as student achievement (Bryk \& Schneider, 2002; Sweetland \& Hoy, 2000; Tschannen-Moran, 2001). Hypothesizing that principal learning-centered leadership is associated with faculty trust in the principal and other variables might also be related to faculty trust in the principal this study sough to answer the following research questions:

- What school and principal demographic variables are associated with faculty trust in the principal?

- To what degree is the learning-centered leadership of a principal associated with faculty trust in that principal? 


\section{Measurement}

This study analyzed data from existing data sets to better understand the relationships between principal learning-centered leadership, faculty trust in the principal, and other principal and school demographic variables. Two separate instruments were used to gather these data sets. First, the learning-centered behaviors of a principal were measured using the Vanderbilt Assessment of Leadership in Education (VAL-ED) instrument developed through Vanderbilt University and the Wallace Foundation. The VAL-ED instrument focuses on principal behaviors associated with learning-centered leadership. The developers identified six core components of school performance that leaders should focus on. Core components refer to principal leadership behaviors that support the learning of students and enhance the ability of teachers to teach. In addition, the instrument also measures six key processes of leadership. The key processes are leadership behaviors traditionally associated with transformational leadership that affect follower's levels of commitment and shape organizational culture. These two aspects of leadership combine to form the construct of learning-centered leadership that is measured by the instrument. The core components and key processes measured by the instrument have been determined after a thorough review of existing literature, state and national standards of principal performance, and other measures of principal behavior.

The VAL-ED instrument is based on a review of learning-centered leadership literature and is aligned with the Interstate School Leaders Licensure Consortium (ISLLC) standards. The instrument has been tested to be both reliable and valid. The instrument was subjected to a multistage developmental process that included cognitive labs, pilot tests, and field tests. The field trial sample consisted of more than 270 schools and over 8,000 individual evaluations with 218 schools having complete sets of responses. The sample included elementary, middle, and high 
schools from all regions of the United States (Porter, Polikoff, Goldring, Murphy, Elliott, \& May, 2010). In addition, the developers of the instrument explored the possibility of having a random half of teachers complete a random half of the items on one form of the VAL-Ed and the other half of the teachers complete the other half of the 72 items. Using data from the national field trial, they investigated the reliability of this approach. They found the one form correlates 0.8 with the other half form when aggregating across teachers in a school. These results justified modifying the instrument. The modified instrument includes a random half of the full 72 item questionnaire. The modified instrument was the version used in this study.

The VAL-ED instrument produced three different scores for each principal assessed. First, a mean score based on the six core components was generated for each principal. Second, a key processes mean score was also produced for each principal. Finally, a total effectiveness score for each principal is produced. The total effectiveness score was a mean score of the core components items and the key processes items from all respondents for each principal.

Faculty trust in principal was measured using the Omnibus T-Scale developed by Hoy \& Tschannen-Moran (2007). The instrument measures multiple dimensions of trust—faculty trust in the principal, in colleagues, and in clients (students and parents). The full instrument consists of 26 Likert items that measure each of the subscales. However, for the data set being used for this study respondents replied only to the 8 items associated with the sub-scale of faculty trust in the principal. Teachers indicated their level of agreement on a 6-point Likert scale from "Strongly Disagree" to "Strongly Agree." The norms for the Faculty Trust Scales are based on a sample of 97 high schools in Ohio, 66 middle schools in Virginia, and 146 elementary schools in Ohio. The reliabilities of the three subscales typically range from .90 to .98 . Factor analytic studies of the Faculty Trust Scale support the construct validity of the measure (Hoy \& 
Tschannen-Moran, 2007). The Omnibus T-Scale provided an aggregate mean faculty trust in the principal score for each principal in the study from each of the respondents in the school.

\section{Representation and Data Collection Process}

This study targeted the principals and faculty members of all the traditional schools in a large suburban school district in the Rocky Mountain region of the United States. Within this district are eight traditional high schools with grades 10-12, twelve junior high schools with grades 7-9, and 55 elementary schools. All non-specialty schools in the district were targeted for participation in the study. The actual data set consists of data from eight high schools, 11 junior high schools, and 40 elementary schools. With district approval, survey instruments were administered at the individual site at a faculty meeting or other scheduled time to all faculty members at each school. The district human resources department generated a list of full time teachers at each school. Researchers invited principals at each of the targeted schools to participate in a study. If they choose to participate, they nominated a site coordinator for the study. The site coordinator did not participate in the actual study. The site coordinator for each school distributed the implied consent form, the instructions, and the access codes associated with the VAL-ED instrument to the teachers. The teachers at each school participated in the VAL-ED survey online by entering a code for their principal and their own unique access code. Within a few days of the teachers receiving the information about the VAL-ED survey, the teachers received an email with a link to the Omnibus T-Scale Faculty Trust in Principal survey. The trust survey was administered through online survey software.

\section{Analysis and Modeling}

The research purpose of this study is to better understand the relationship between the learning-centered leadership of a principal and faculty trust in the principal. The data were first 
analyzed to make the sure the data sets are complete including the relevant demographical data for each principal and school. Researchers determined aggregate mean leadership effectiveness and trust scores for each principal. They also determined mean scores for each of the control or demographic variables. Principal learning-centered leadership served as the explanatory variable and faculty trust in the principal as the dependent or outcome variable. Principal and school demographic variables served as other possible explanatory variables.

After determining the overall learning-centered leadership score and faculty trust score, bivariate analyses explored possible relationships between faculty trust in the principal and the school and principal demographic variables. The analysis included principal learning-centered leadership as one of the variables associated with the principal. These bivariate analyses assessed if faculty trust in the principal was related to any of the variables without adjusting for the influence of any other variable. The school demographic variables used in this analysis were the following: school level, school size, percent of faculty female, mean years of faculty experience, percentage of minority students, percentage of poverty students, and the school achievement grade. The principal demographic variables were: principal age, gender, years in administration, years with faculty, and leadership score.

The next level of analysis consisted of building models of trust using multiple linear regressions. These analyses explored the significance of the relationship between principal learning-centered leadership and faculty trust in the principal while adjusting for the influence of principal and school characteristics on that trust. The purpose of this analysis was to determine the model that best described faculty trust in the principal. The multiple linear regressions considered the demographic or characteristic variables individually to determine their relationship with faculty trust in the principal and their interaction with principal learning- 
centered leadership within the context of the learning-centered leadership and faculty trust in the principal.

These analyses were done to answer the research questions proposed by this study. Multiple linear regression analysis models were developed and assessed to determine what model best explained the relationship of the hypothesized variables and the outcome variable. Given the purpose of the study, the data, and the method of analysis, the study is limited in its ability to support a causal relationship between the learning-centered behavior of a principal and faculty trust in the principal. 


\section{DISSERTATION REFERENCES}

Bell, L., Bolam, R., \& Cubillo, L. (2003). A systematic review of the impact of school leadership and management on student outcomes. EPPI-Centre, Social Science Research Unit, Institute of Education: University of London.

Bird, J. J., Wang, C., Watson, J. R., \& Murray, L. (2009). Relationships among principal authentic leadership and teacher trust and engagement levels. Journal of School Leadership, 19(2), 153-171.

Bossert, S. T., Dwyer, D. C., Rowan, B, \& Lee, G. V. (1982). The instructional management role of the principal. Educational Administration Quarterly, 18(3), 34-64.

Bridges, E. M. (1982). Research on the school administrator: The state of the art, 1967-1980. Educational Administration Quarterly, 18(3), 12-33.

Brookover, W. B., \& Lezotte, L. W. (1979). Changes in school characteristics coincident with changes in student achievement (C. o. Education, Trans.) (pp. 1 - 116). Michigan State University, East Lansing, Michigan: The Institute for Research on Teaching.

Bryk, A., \& Schneider, B. (2002). Trust in schools: A core resource for improvement. New York, NY: Russell Sage Foundation.

Burke, C. S., Sims, D. E., Lazzara, E. H., \& Salas, E. (2007). Trust in leadership: A multi-review and integration. The Leadership Quarterly, 18(6), 606-632.

Coleman, J. (1968). The concept of equality of educational opportunity. Harvard Educational Review, 38(1), 7-22.

Cotton, K. (2003). Principals and student achievement: What the research says. Alexandria, VA: Association for Supervision and Curriculum Development. 
Dirks, K. T., \& Ferrin, D. L. (2001). The role of trust in organizational settings. Organization Science, 12(4), 450-467.

Dirks, K. T., \& Ferrin, D. L. (2002). Trust in leadership: Meta-analytic findings and implications for research and practice. Journal of Applied Psychology, 87(4), 611-628.

DuFour, R. (2002). The learning-centered principal. Educational Leadership, 59(8), 12-15.

Edmonds, R. (1979). Effective schools for the urban poor. Educational Leadership, 37(1), 15-24.

Figlio, D., \& Loeb, S. (2011). School accountability. Handbook of the Economics of Education, $3,383-421$.

Goddard, R. D., Hoy, W. K., \& Hoy, A. W. (2000). Collective teacher efficacy: Its meaning, measure, and impact on student achievement. American Educational Research Journal, 37(2), 479 .

Goddard, R. D., Salloum, S. J., \& Berebitsky, D. (2009). Trust as a mediator of the realtionships between poverty, racial composition, and academic achievement: Evidence from Michigan's public elementary schools. Educational Administration Quarterly, 45(2), 292-311.

Goddard, Y. L., Goddard, R. D., \& Tschannen-Moran, M. (2007). A theoretical and empirical investigation of teacher collaboration for school improvement and student achievement in public elementary schools. Teachers College Record, 109(4), 877-896.

Goldring, E., Cravens, X. C., Murphy, J., Porter, A. C., Elliott, S. N., \& Carson, B. (2009). The evaluation of principals: What and how do states and urban districts assess leadership? The Elementary School Journal, 110(1), 19-39. 
Goldring, E., Porter, A., Murphy, J., Elliot, S. N., \& Cravens, X. C. (2009). Assessing learningcentered leadership: Connections to research, professional standards, and current practices. Leadership and Policy in Schools, 8(1), 1-36.

Hallinger, P. (2003). Leading educational change: Reflections on the practice of instructional and transformational leadership. Cambridge Journal of Education, 33(3), 329-352.

Hallinger, P. (2011). A review of three decades of doctoral studies using the Principal Instructional Management Rating Scale: A lens on methodological progress in educational leadership. Educational Administration Quarterly, 47(2), 271-306.

Hallinger, P., \& Murphy, J. (1985). Assessing the instructional management behavior of principals. The Elementary School Journal, 86(2), 217-247.

Hallinger, P., \& Heck, R. H. (1996). Reassessing the principal's role in school effectiveness: A review of empirical research, 1980-1995. Educational Administration Quarterly, 32(1), $5-44$.

Hallinger, P., \& Heck, R. H. (2010). Leadership for learning: Does collaborative leadership make a difference in school improvement? Educational Management Administration \& Leadership, 38(6), 654-678.

Hanushek, E. A., \& Raymond, M. E. (2005). Does school accountability lead to improved student performance? Journal of Policy Analysis and Management, 24(2), 297-327.

Hattie, J. (2009). Visible learning: A synthesis of 800+ meta-analyses on achievement. New York, NY: Routledge.

Hoy, W. K., Gage, C. Q. III, \& Tarter, J.C. (2006). School mindfulness and faculty trust: Necessary conditions for each other? Educational Administration Quarterly, 42(2), 236255. 
Hoy, W. K., Smith, P. A., \& Sweetland, S. R. (2002). The development of the organizational climate index for high schools: Its measure and relationship to faculty trust. The High School Journal, 86(2), 38-49.

Hoy, W. K., \& Sweetland, S. R. (2001). Designing better schools: The meaning and measure of enabling school structures. Educational Administration Quarterly, 37(3), 296-321.

Hoy, W. K., \& Tarter, J. C. (2004). Organizational justice in schools: No justice without trust. International Journal of Educational Management, 18(4), 250-259.

Hoy, W. K., \& Tschannen-Moran, M. (1999). Five faces of trust: An empirical confirmation in urban elementary schools. Journal of School Leadership, 9, 184-208.

Hoy, W. K. \& Tschannen-Moran, M. (2003). The conceptualization and measurement of faculty trust in schools: The omnibus T-scale. In W.K. Hoy \& C.G. Miskel, Studies in Leading and Organizing Schools (pp. 181-208). Greenwich, CT: Information Age Publishing.

Knapp, M. S., Copland, M. A., Honig, M. I., Plecki, M. L., \& Portin, B. S. (2010). Learningfocused leadership and leadership support: Meaning and practice in urban systems. Seattle: University of Washington, Center for the Study of Teaching \& Policy.

Knapp, M. S., Copland, M. A., \& Talbert, J. E. (2003). Leading for learning: Reflective tools for school and district leaders. Seattle: University of Washigton, Center for the Study of Teaching and Policy.

Kramer, R. M. (1999). Trust and distrust in organizations: Emerging perspectives, enduring questions. Annual Review of Psychology, 50(1), 569-598.

Lambert, L. (2002). A framework for shared leadership. Educational Leadership, 59(8), 37-40.

Leithwood, K., Harris, A., \& Hopkins, D. (2008). Seven strong claims about successful school leadership. School Leadership and Management, 28(1), 27-42. 
Leithwood, K., \& Jantzi, D. (2005). A review of transformational school leadership research 1996 - 2005. Leadership and Policy in Schools, 4(3), 177-199.

Leithwood, K., Louis, K. S., Anderson, S., \& Wahlstrom, K. (2004). How leadership influences student learning: A review of research for the Learning from Leadership project. New York, NY: The Wallace Foundation.

Louis, K. S. (2007). Trust and improvement in schools. Journal of Educational Change, 8(1), 124.

Louis, K. S., \& Wahlstrom, K. (2011). Principals as cultural leaders: Principals shape the culture in positive ways when they share leadership and take responsibility for shaping classroom improvements. Phi Delta Kappan, 92(5), 52-56.

Marks, H. M., \& Printy, S. M. (2003). Principal leadership and school performance: An integration of transformational and instructional leadership. Educational Administration Quarterly, 39(3), 370-397.

Marzano, R. J., Waters, T., \& McNulty, B. A. (2005). School leadership that works: From research to results. Alexandria, VA: Association for Supervision and Curriculum Development.

Mayer, R. C., Davis, J. H., \& Schoorman, D. F. (1995). An integrative model of organizational trust. Academy of Management Review, 20(3), 709-734.

Mishra, A. K. (1996). Organizational responses to crisis: The centrality of trust. In R. M. Kramer \& T. Tyler (Eds.), Trust in Organizations (pp. 261-287). Newbury Park, CA: Sage.

Moye, M. J., Henkin, A. B., \& Egley, R. J. (2005). Teacher-principal relationships: Exploring linkages between empowerment and interpersonal trust. Journal of Educational Administration, 43(3), 260-277. 
Murphy, J. (1988). Methodological, measurement, and conceptual problems in the study of instructional leadership. Educational Evaluation and Policy Analysis, 10(2), 117-139.

Murphy, J., Elliott, S. N., Goldring, E., \& Porter, A. C. (2008). Learning-Centered leadership: A Conceptual Foundation. New York, NY: The Wallace Foundation.

Murphy, J., Hallinger, P., \& Mitman, A. (1983). Problems with research on educational leadership: Issues to be addressed. Educational Evaluation and Policy Analysis, 5(3), 297-305.

Pitner, N. (1988). The study of administrator effects and effectiveness. The Handbook of Research on Educational Administration: A Project of the American Educational Research (pp. 99-122). San Francisco, CA: Jossey-Bass Publishers.

Porter, A. C., Polikoff, M. S., Goldring, E. B., Murphy, J., Elliott, S. N., \& May, H. (2010). Investigating the validity and reliability of the Vanderbilt assessment of leadership in education. The Elementary School Journal, 111(2), 282-313.

Robinson, V. M. (2010). From instructional leadership to leadership capabilities: Empirical findings and methodological challenges. Leadership and Policy in Schools, 9(1), 1-26.

Robinson, V. M., Lloyd, C. A., \& Rowe, K. J. (2008). The impact of leadership on student outcomes: An analysis of the differential effects of leadership types. Educational Administration Quarterly, 44(5), 635-674.

Rousseau, D. M., Sitkin, S. B., Burt, R. S., \& Camerer, C. (1998). Not so different after all: A cross-discipline view of trust. Academy of Management Review, 23(3), 393-404.

Smylie, M. A., Bennett, A., Konkol, P., \& Fendt, C. R. (2005). What do we know about developing school leaders? A look at existing research and next steps for new study. In 
W. A. Firestone \& C. Riehl (Eds.), A New Agenda for Research in Educational Leadership (pp. 138-155). New York, NY: Teachers College Press.

Sweetland, S. R., \& Hoy, W. K. (2000). School characteristics and educational outcomes: Toward an organizational model of student achievement in middle schools. Educational Administration Quarterly, 36(5), 703-729.

Tarter, J. C., Bliss, J. R., \& Hoy, W. K. (1989). School characteristics and faculty trust in secondary schools. Educational Administration Quarterly, 25(3), 294-308.

Tschannen-Moran, M. (2001). Collaboration and the need for trust. Journal of Educational Administration, 39(4), 308-331.

Tschannen-Moran, M. (2003). Fostering organizational citizenship in schools. Studies in Leading and Organizing Schools (pp. 157-179). Greenwich, CT: Information Age Publishing.

Tschannen-Moran, M. (2004). Trust Matters: Leadership for Successful Schools. San Francisco, CA: Jossey-Bass Publishers.

Tschannen-Moran, M. (2009). Fostering teacher professionalism in schools: The role of leadership orientation and trust. Educational Administration Quarterly, 45(2), 217-247.

Tschannen-Moran, M., \& Hoy, W. K. (2000). A multidisciplinary analysis of the nature, meaning, and measurement of trust. Review of Educational Research, 70(4), 547-593.

Weber, G. (1971). Inner City Can Be Taught To Read: Four Successful Schools. CBE Occasional Papers, No. 18 (pp. 1 - 41). Washington, D.C.: Council for Basic Education. Wiliam, D. (2010). Standardized testing and school accountability. Educational Psychologist, $45(2), 107-122$. 
Witziers, B., Bosker, R. J., \& Kruger, M. L. (2003). Educational leadership and student achievement: The elusive search for an association. Educational Administration Quarterly, 39(3), 398-425. 